\title{
CO Hydrogenation Reaction on Sulfided Molybdenum Catalysts
}

\author{
Xue-Rong Shi ${ }^{1,2}$, Haijun Jiao ${ }^{1,3}$, Klaus Hermann ${ }^{2 *}$, and Jianguo Wang ${ }^{{ }^{*}}$
}

1) State Key Laboratory of Coal Conversion, Institute of Coal Chemistry, Chinese Academy of Sciences, Taiyuan, Shanxi 030001 (China).

2) Theory Department, Fritz-Haber-Institut der MPG, Faradayweg 4-6, D-14195 Berlin and Collaborative Research Center Sfb 546, Berlin (Germany).

3) Leibniz-Institut für Katalyse e.V. an der Universität Rostock, Albert-Einstein-Strasse 29a, 18059 Rostock (Germany).

* Corresponding authors: K. Hermann (hermann@,fhi-berlin.mpg.de);

J. Wang (iccjgw@sxicc.ac.cn)

Keywords: CO hydrogenation, molybdenum disulfide, intermediate surface species, DFT studies.

\begin{abstract}
Adsorption of reaction intermediates appearing during CO hydrogenation at the sulfur covered $\mathrm{MoS}_{2}(10-10)$ surfaces, Mo-termination with $42 \% \mathrm{~S}$ coverage and S-termination with $50 \% \mathrm{~S}$ coverage, are investigated systematically using periodic density functional theory methods. Computed vibrational frequencies of all intermediates are compared with observed data from infrared (IR) spectroscopy allowing a detailed interpretation and assignment of the different features in the experimental spectra. The pathway for CO hydrogenation on both terminations has been studied in detail where the most likely reaction path involves $C_{1}$ type surface species in the sequence

$$
\mathrm{CO} \rightarrow \mathrm{CHO} \rightarrow \mathrm{CH}_{2} \mathrm{O} \rightarrow \mathrm{CH}_{2} \mathrm{OH} \rightarrow \mathrm{CH}_{2} \rightarrow \mathrm{CH}_{3} \rightarrow \mathrm{CH}_{4}
$$
\end{abstract}

in agreement with experiment. 


\section{INTRODUCTION}

Sulfided Mo catalysts have been widely used in hydrodesulfurization (HDS) and hydrodenitrogenation (HDN) processes and exhibit also high activity for methanation and for the Fischer-Tropsch synthesis of light hydrocarbons from CO hydrogenation [1-7]. In particular, CO hydrogenation on sulfided Mo catalysts has been studied extensively because of the tolerance of these catalysts to sulfur poisoning [2-7]. Using in-situ diffuse reflectance infrared Fourier transform (DRIFT) spectroscopy, Koizumi et al. [8] identified the main products of CO hydrogenation on pure $\mathrm{MoS}_{2}$ catalyst to be $\mathrm{CO}_{2}$ and $\mathrm{CH}_{4}$. However, the modification of the pure $\mathrm{MoS}_{2}$ surface by alkali promoters yields alcohols instead of hydrocarbons as while additional promoters, such as Ni or Co, are found to increase the selectivity of ethanol and higher alcohols [9-11].

The CO hydrogenation mechanism, involving formation and breaking of $\mathrm{C}-\mathrm{H}, \mathrm{O}-\mathrm{H}$, and $\mathrm{C}-\mathrm{C}$ bonds, is rather complicated and various reaction schemes have been proposed [12-15] so far. The basic process has been described by reaction steps (1)

$$
\mathrm{CO}+3 \mathrm{H} \rightarrow \mathrm{CHO}+2 \mathrm{H} \rightarrow \mathrm{CH}_{2} \mathrm{O}+\mathrm{H} \rightarrow \mathrm{CH}_{3} \mathrm{O}
$$

occurring at the catalyst surface followed by competing steps (2) [16]

- $\mathrm{CH}_{3} \mathrm{O}+2 \mathrm{H} \rightarrow \mathrm{CH}_{3}+\left(\mathrm{H}_{2} \mathrm{O}\right)_{\text {gas }}$ followed by

$$
\mathrm{CH}_{3}+\mathrm{H} \rightarrow\left(\mathrm{CH}_{4}\right)_{\text {gas }} \text { or by } \mathrm{CH}_{3}+\mathrm{CO}+3 \mathrm{H} \rightarrow\left(\mathrm{CH}_{3} \mathrm{CH}_{2} \mathrm{OH}\right)_{\text {gas }}
$$

- $\mathrm{CH}_{3} \mathrm{O}+\mathrm{H} \rightarrow\left(\mathrm{CH}_{3} \mathrm{OH}\right)_{\text {gas }}$

- $\mathrm{CH}_{3} \mathrm{O}+\mathrm{CO}+\mathrm{H} \rightarrow \mathrm{CH}_{3} \mathrm{COO}+\mathrm{H} \rightarrow\left(\mathrm{HCOOCH}_{3}\right)_{\text {gas }}$

producing alcohols (steps $(2 \mathrm{a}),(2 \mathrm{~b})$ ) or formate (steps (2c), the latter will also form alcohols in subsequent reaction steps). In this context, the existence and details of reaction intermediates have been discussed for a long time but still remain unclear. As examples we mention temperature programmed desorption (TPD) experiments that suggest that formyl (CHO) intermediates are formed at the catalyst surface which, depending on the reaction conditions and the nature of the active sites, may be hydrogenated to yield alcohols or may react to form other hydrocarbons [17-19]. It is also suggested that the primary product is methanol and the methanol could then undergo secondary reactions to produce methane. $\mathrm{H}_{2} \mathrm{O}$ and $\mathrm{CO}_{2}$ formation may take place before methanol desorbing from the surface during high-pressure $\mathrm{CO}$ hydrogenation. Further, experiments of CO hydrogena- 
tion on a sulfided $\mathrm{Mo} / \gamma-\mathrm{Al}_{2} \mathrm{O}_{3}$ catalyst using in-situ DRIFT spectroscopy show vibrational frequency bands where those at 1590,1420 and $1385 \mathrm{~cm}^{-1}$ are claimed to indicate surface formate ( $\mathrm{HCOO}$ ), while an additional band at $1470 \mathrm{~cm}^{-1}$ could originate from acetate $\left(\mathrm{CH}_{3} \mathrm{COO}\right)$, methoxy $\left(\mathrm{CH}_{3} \mathrm{O}\right)$, or from carbonate $\left(\mathrm{CO}_{3}\right)$ species [8]. Despite these experimental efforts theoretical work has been restricted mainly to $\mathrm{CO}, \mathrm{H}_{2}$ adsorption and surface properties of $\mathrm{MoS}_{2}$ [20-31]. Using a periodic two-sheet model (for the definition of sheets see Sec. 2 below) of the ideal $\mathrm{MoS}_{2}(10-10)$ surface, Cristol et al. [29] found that dissociative $\mathrm{H}_{2}$ adsorption is endothermic at the Mo terminated sheet with $50 \% \mathrm{~S}$ coverage while it is exothermic for $33 \% \mathrm{~S}$ coverage forming one S-H and one Mo-H group.

Using a periodic single-sheet model, Sun et al. [28] studied $\mathrm{H}_{2}$ adsorption and dissociation on $\mathrm{MoS}_{2}$ and NiMoS, and found that homolytic $\mathrm{H}_{2}$ dissociation to form two $\mathrm{S}-\mathrm{H}$ groups is thermodynamically preferred over heterolytic dissociation yielding one S-H and one Mo-H group, and the latter is kinetically favored. On the other hand, Bollinger et al. [27] found the most stable hydrogen adsorption to be the formation of two S-H groups on the S edge. By means of IR spectroscopy and applying a two-sheet periodic model Travert et al. [32] reported CO adsorption on sulfided Mo catalysts and compared the results of spectroscopic with theoretical studies. They found that under reductive condition adsorption of one $\mathrm{CO}$ molecule at the sulfur edge with about $50 \% \mathrm{~S}$ coverage is the most stable and exothermic by $0.7 \mathrm{eV}$. They also identified three thermodynamically stable surfaces for different $\mathrm{H}_{2} / \mathrm{H}_{2} \mathrm{~S}$ pressure ratios which were also studied by Schweiger et al. [24], Bollinger et al. [27], Raybaud et al. [33] and Cristol et al. [34].

While a considerable amount of experimental studies have been carried out, theoretical investigations on $\mathrm{CO}$ hydrogenation at the pure $\mathrm{MoS}_{2}$ surface are still lacking. Recently, Huang and Cho have studied CO hydrogenation at the $\mathrm{MoS}_{2}(10-10)$ surface [35] where they considering two terminations reflecting full Mo metal and full sulfur coverage. They found that the most likely products of $\mathrm{CO}$ hydrogenation are $\mathrm{CH}_{4}$ and $\mathrm{CO}_{2}$, in agreement with the experiment results [8]. However, according to the studies of Travert et al. [32], Cristol et al. [29,34], Raybaud et al. [33], and Sun et al. [28,36], the two terminations considered by Huang and Cho [35] do not seem to reflect the realistic catalyst. They are not stable for $\mathrm{H}_{2} \mathrm{~S} / \mathrm{H}_{2}$ pressure ratios in the range $0.0001<\mathrm{p}\left(\mathrm{H}_{2} \mathrm{~S}\right) / \mathrm{p}\left(\mathrm{H}_{2}\right)<10000$ [34]. For $\mathrm{p}\left(\mathrm{H}_{2} \mathrm{~S}\right) / \mathrm{p}\left(\mathrm{H}_{2}\right)<0.05$ corresponding to the realistic catalytic system the $\mathrm{MoS}_{2}(10-10)$ surface is terminated by Mo metal sheets covered with about $50 \%$ sulfur and by S sheets with about 
$50 \%$ sulfur vacancies $[28,29,32-34,36]$ as mentioned above. These terminations have been considered in the present work.

We apply ab initio density functional theory (DFT) methods together with periodic surface models to examine all intermediates of the above described CO hydrogenation reaction steps [16]. We focus on geometric and energetic parameters of the adsorbed species as well as on their vibrational properties in connection with the interpretation of the corresponding experimental data from IR measurements. The intermediates are $\mathrm{C}_{1}$-type $\mathrm{CH}_{\mathrm{x}}, \mathrm{CH}_{\mathrm{x}} \mathrm{OH}(\mathrm{x}=0,1,2), \mathrm{CH}_{\mathrm{x}} \mathrm{O}(\mathrm{x}=1,2,3)$, $\mathrm{HCOO}$ and $\mathrm{CO}_{3}$ which lead to $\mathrm{C}_{1}$-type products found over pure $\mathrm{MoS}_{2}$ catalysts [16]. We also consider $\mathrm{C}_{2}$-type intermediates $\mathrm{CH}_{3} \mathrm{COO}, \mathrm{CH}_{3} \mathrm{CO}, \mathrm{CH}_{3} \mathrm{CHO}$ and $\mathrm{CH}_{3} \mathrm{CH}_{2} \mathrm{O}$. In addition, possible reaction paths of CO hydrogenation have been explored.

Sec. 2 describes briefly model geometries and computational methods while Sec. 3 presents the theoretical results and discussion. Finally, we summarize our conclusions in Sec. 4.

\section{THEORETICAL DETAILS}

Clean $\mathrm{MoS}_{2}$ forms a hexagonal lattice with two elemental units in the elementary cell. The lattice is layer type with weakly coupling $\mathrm{MoS}_{2}$ sheets oriented along the (0001) direction of the crystal. The orientation of the reactive surface is assumed to be (10-10) [36] where the ideal bulk terminated geometry is described by parallel pairs of $\mathrm{MoS}_{2}$ sheets perpendicular to the surface (Fig. 1a). Each pair consists of two differently terminated sheets, one of Mo and one of S termination which may offer active sites for catalytic reactions. Theoretical thermodynamic studies on the $\mathrm{MoS}_{2}(10-10)$ surface at different $\mathrm{H}_{2} \mathrm{~S} / \mathrm{H}_{2}$ exposures [28,29,32-34,36] have shown that under hydrogen-rich conditions i.e.; for $\mathrm{H}_{2} \mathrm{~S} / \mathrm{H}_{2}$ pressure ratios $<0.05$ reflecting realistic reaction conditions, the two non-equivalent sheets are both terminated by sulfur, one sulfur atom per surface molybdenum, however, with the surface sulfur positioned differently. Compared with the ideal surface this sulfur reconstructed geometry (Fig. 1b) corresponds to sulfur addition at the initial Mo terminated sheet (denoted $\mathrm{T}_{1}$ termination) and sulfur depletion at the $\mathrm{S}$ terminated sheet (denoted $\mathrm{T}_{2}$ termination). Lauritsen et al. [37] observed $\mathrm{C}_{4} \mathrm{H}_{7} \mathrm{~S}$ species adsorbed at the brim edge of triangular $\mathrm{MoS}_{2}$ nanoclusters by scanning tunneling microscopy (STM) and concluded that the brim edge is a new 
kind of active site for HDS. However, so far there is no experimental evidence to indicate that CO hydrogenation can also occur at this brim edge. Triangular $\mathrm{MoS}_{2}$ nanoclusters observed by Lauritsen exist usually under $\mathrm{H}_{2} \mathrm{~S}$ rich conditions during the HDS process which is not considered in this work.

The $\mathrm{T}_{1}$ and $\mathrm{T}_{2}$ terminated sheets, including adsorption of reaction intermediates, are examined in separate calculations where supercell model systems with only one sheet termination are used. Here slabs of identical sheets, either $\mathrm{T}_{1}$ or $\mathrm{T}_{2}$ terminated, containing four rows of molybdenum atoms and corresponding rows of sulfur atoms in each slab (Fig. 2a, b) are placed periodically with a separation of $10 \AA$ of vacuum along the (0001) direction. The slabs are repeated periodically along the surface normal (equal to the (10-10) direction) with a vacuum separation of $10 \AA$ between them. Test calculations confirmed that the chosen separation was sufficient to avoid electronic coupling between adjacent slabs. Theoretical studies for the $\mathrm{T}_{1}$ model system have shown [28] that for low $\mathrm{H}_{2} \mathrm{~S} / \mathrm{H}_{2}$ pressure ratios the surface can become more stable thermodynamically if the sulfur concentration at the top is smaller than one S atom per underlying Mo atom. This can be achieved by including surface sulfur vacancies (leaving coordinatively unsaturated molybdenum surface sites) where, assuming $\mathrm{H}_{2} \mathrm{~S} / \mathrm{H}_{2}$ pressure ratios below 0.001 , a reasonable value is one vacancy per six surface sulfur atoms corresponding to $42 \%$ relative S coverage (100\% S coverage corresponds two surface S atoms per Mo atom [33]) at the real $\mathrm{MoS}_{2}(10-10)$ surface as sketched in Figs. 1b, 2a. [28] This model geometry, labeled $\mathrm{T}_{1}{ }^{\prime}$, is described by a sheet supercell with six $\operatorname{MoS}_{\mathrm{x}}$ units along the surface edge and will be considered in the following. Adsorption of reaction intermediates at the sheet edges of the $\mathrm{T}_{1}{ }^{\prime}$ and $\mathrm{T}_{2}$ model systems is considered in corresponding geometry optimizations where the adsorbates and the top-most substrate layers are allowed to relax freely while the two bottom layers of the slabs (Fig. 2) are fixed at the geometry of bulk $\mathrm{MoS}_{2}$.

The electronic structure and equilibrium geometries of the model systems are calculated using the $\mathrm{DMol}^{3}$ program package $[38,39]$ where the generalized gradient corrected functional according to Perdew and Wang (PW91) is employed [40,41]. Extended numerical all-electron basis sets (double-zeta plus polarization, DNP) are used to describe the electronic structure of all atoms in the model systems except molybdenum where the 28-electron core is approximated by an effective core potential (ECP) $[42,43]$ and a DNP basis is used to account for the valence electron structure. All electronic states are determined by calculations including spin polarization for the open shell species 
in gas phase and for appropriate multiplet states of the adsorption systems. As a result of the large supercells the $\mathrm{k}$ point integration during the electronic structure calculations is restricted to one $\mathrm{k}$ point in the Brillouin zone. Geometry optimizations are performed with a numerical displacement accuracy of the atom centers of $5 \times 10^{-3} \AA$. Possible transition states (TS) are located by using the complete linear and quadratic synchronous transit (LST, QST) method [44] connecting the most stable reactants and products. Corresponding adsorption energies, $\mathrm{E}_{\mathrm{ads}}$, are computed from appropriate differences of total energies of supercells of the $\mathrm{MoS}_{2}$ slabs with adsorbates in their equilibrium geometries, $\mathrm{E}_{\text {tot }}(\mathrm{slab} / \mathrm{ads})$, of the pure $\mathrm{MoS}_{2}$ slabs, $\mathrm{E}_{\text {tot }}(\mathrm{slab})$, and of the free adsorbates in gas phase, $\mathrm{E}_{\text {tot }}(\mathrm{ads})$, i.e. by

$$
\mathrm{E}_{\mathrm{ads}}=\mathrm{E}_{\mathrm{tot}}(\mathrm{slab} / \mathrm{ads})-\mathrm{E}_{\mathrm{tot}}(\mathrm{slab})-\mathrm{E}_{\mathrm{tot}}(\mathrm{ads})
$$

where negative $\mathrm{E}_{\mathrm{ads}}$ values correspond to exothermic adsorption while positive $\mathrm{E}_{\text {ads }}$ means endothermic adsorption. The adsorption energies (3) are evaluated using total energies $E_{\text {tot }}(\mathrm{ads})$ of the gas phase species in their neutral ground states. This is justified since the corresponding experiments have been carried out at $\mathrm{T}=500-700 \mathrm{~K}$ where there is no solvent to provide charges. However, the corresponding adsorbates may become charged at the surface as a result of charge transfer which is accounted for by the selfconsistent treatment of the combined adsorbate-substrate system (slab/ads) in its neutral state.

The present calculations consider periodic slabs where the molecular adsorbates and reactants are added only on one side of the slab. This yields a non-symmetric slab system where in strongly polar systems charge rearrangements may result in large dipole contributions affecting the accuracy of the adsorption energies $\mathrm{E}_{\text {ads. }}$. This was studied in test calculations for the adsorption of formyl, CHO and formate, $\mathrm{HCOO}$, at the $\mathrm{T}_{1}$ ' terminated $\mathrm{MoS}_{2}$ surface employing the Vienna Ab Initio Simulation Package (VASP) $[45,46]$ (The DMol ${ }^{3}$ code does not allow including dipole corrections in a straightforward way.) Dipole corrections were found to contribute to $\mathrm{E}_{\text {ads }}$ less than $0.04 \mathrm{eV}$ for CHO and $0.05 \mathrm{eV}$ for HCOO, respectively ( $2 \%$ of $\mathrm{E}_{\mathrm{ads}}$ in both cases) which suggests strongly that these corrections can be ignored for the present purpose. The non-symmetric slab system has also been successfully applied by other groups using the $\mathrm{DMol}^{3}$ code in theoretical studies on $\mathrm{CO}, \mathrm{H}_{2}$ adsorption, surface properties, and surface reactions at $\mathrm{MoS}_{2}$ surfaces [28,35,36,47]. As specific examples, we mention work by Todorova et al. [47] on the hydrogenolysis reaction of $\mathrm{CH}_{3} \mathrm{SH}$ to 
$\mathrm{CH}_{4}$ at the $\mathrm{MoS}_{2}(10-10)$ surface and by Huang et al. [35] on CO hydrogenation at prefect $\mathrm{MoS}_{2}(10-10)$ corresponding to our $\mathrm{T}_{1}$ model.

In addition to geometric and energetic quantities, adsorbate charges $q$ are determined by Mulliken charges summed over all atoms of the adsorbates. (It should be emphasized that all adsorbate charges based on Mulliken populations can be considered only as qualitative guidelines and not taken as quantitative entities of chemical relevance. In particular, they cannot represent formal valence charges.) Further, vibrational frequencies of the adsorbates are calculated following the harmonic approach using Hessian matrices where all substrate centers are fixed and only intra-adsorbate displacements are considered.

The calculations include reactions of the different intermediates of CO hydrogenation at the $\mathrm{MoS}_{2}(10-10)$ surface. For a reaction $\mathrm{A}+\mathrm{B} \rightarrow \mathrm{AB}$ we define two different reaction scenarios. First we consider two separate species A, B at the surface which approach and react to form the product $\mathrm{AB}$. This is described by a reaction energy $\Delta \mathrm{E}_{\text {sep }}$ with

$$
\Delta \mathrm{E}_{\text {sep }}=\left[\mathrm{E}_{\mathrm{tot}}(\mathrm{slab} / \mathrm{AB})+\mathrm{E}_{\mathrm{tot}}(\mathrm{slab})\right]-\left[\mathrm{E}_{\mathrm{tot}}(\mathrm{slab} / \mathrm{A})+\mathrm{E}_{\mathrm{tot}}(\mathrm{slab} / \mathrm{B})\right],
$$

where $E_{\text {tot }}$ are total energies (per unit cell) of the corresponding systems. Second, we consider the two species A, B in a coadsorption geometry where they stabilize at nearby sites followed by a reaction to form $\mathrm{AB}$. This is described by a reaction energy $\Delta \mathrm{E}_{\mathrm{coad}}$ with

$$
\Delta \mathrm{E}_{\text {coad }}=\mathrm{E}_{\text {tot }}(\mathrm{slab} / \mathrm{AB})-\mathrm{E}_{\text {tot }}\left(\mathrm{slab} /(\mathrm{A}+\mathrm{B})_{\text {coad }}\right)
$$

where $E_{\text {tot }}\left(\mathrm{slab} /(\mathrm{A}+\mathrm{B})_{\text {coad }}\right)$ denotes the total energy of the coadsorption system. Obviously, the difference $\left(\Delta \mathrm{E}_{\text {coad }}-\Delta \mathrm{E}_{\mathrm{sep}}\right)$ characterizes the interaction between $\mathrm{A}$ and $\mathrm{B}$ in the coadsorbed state at the surface with negative values for attraction and positive ones for repulsion. In Sec. 3, we will focus on the discussion of results for $\Delta \mathrm{E}_{\mathrm{coad}}$.

\section{RESULTS AND DISCUSSION}

\subsection{Adsorption of reaction intermediates}


Table 1 lists the computed adsorption energies $\mathrm{E}_{\text {ads }}$ and adsorbate charges $q$ of 16 possible intermediates occurring in $\mathrm{CO}$ hydrogenation reactions discussed above where stabilization at $\mathrm{T}_{1}{ }^{\prime}$ and $\mathrm{T}_{2}$ terminated $\mathrm{MoS}_{2}$ model surfaces is considered. As mentioned above, adsorption energies are evaluated using total energies $\mathrm{E}_{\mathrm{tot}}(\mathrm{ads})$ of the gas phase species in their neutral ground states where charging like in the presence of a solvent is excluded. In addition, Figs. 3, 4 and 5 show the corresponding equilibrium geometries of the intermediates for both terminations. Here only adsorbate sites and geometries with largest $\mathrm{E}_{\text {ads }}$ are included while many more have been evaluated. In addition, for $\mathrm{T}_{1}$ ' terminated $\mathrm{MoS}_{2}$ we focus only on adsorption near the coordinatively unsaturated molybdenum surface site which is well accepted to play a major role in the adsorption and activation of the reactants $[48-50]$. All intermediate adsorbates stabilize at $T_{1}{ }^{\prime}$ and $T_{2}$ terminated $\mathrm{MoS}_{2}$ surfaces resulting in basically two different adsorption geometries where the adsorbate is bound to either one or two molybdenum centers as will be discussed in the following.

\subsubsection{Adsorbed $\mathrm{C}_{1} \mathrm{H}_{\mathrm{x}} \mathrm{O}_{\mathrm{y}}$ species}

Extended optimizations of formyl, CHO, at the $\mathrm{MoS}_{2}$ model surface yield for $\mathrm{T}_{1}{ }^{\prime}$ and $\mathrm{T}_{2}$ termination three different local energy minima each where those of the most stable states for each termination are shown by their equilibrium geometries in Fig. 3a. Here the CO part is always found to bridge two adjacent molybdenum centers resulting in $\mathrm{E}_{\mathrm{ads}}$ of $-2.01 \mathrm{eV}\left(\mathrm{T}_{1}{ }^{\prime}\right)$ and $-1.98 \mathrm{eV}\left(\mathrm{T}_{2}\right)$ (Table 1a). Further, the $\mathrm{C}-\mathrm{O}$ bond of the adsorbate is activated compared with free $\mathrm{CHO}$ increasing its $\mathrm{C}-\mathrm{O}$ bond length from $1.19 \AA$ to $1.25\left(\mathrm{~T}_{1}{ }^{\prime}\right)$ and $1.26 \AA\left(\mathrm{T}_{2}\right)$, respectively. Such C-O distance increase has also been obtained for $\mathrm{COH}, \mathrm{CH}_{2} \mathrm{O}, \mathrm{CH}_{3} \mathrm{O}, \mathrm{CHOH}$ and $\mathrm{CH}_{2} \mathrm{OH}$ (see below), where the effect is smallest for $\mathrm{COH}$ adsorbed at $\mathrm{T}_{2}$ terminated $\mathrm{MoS}_{2}$. The latter is explained by the fact that the adsorbate binds only with its carbon end to one Mo substrate atom (Fig. 3b), affecting the C-O bond only little. For hydroxy carbine, $\mathbf{C O H}$, two different local energy minima are obtained for $\mathrm{T}_{1}{ }^{\prime}$ and one for $\mathrm{T}_{2}$ terminated $\mathrm{MoS}_{2}$ surface. Here the most stable adsorbate geometry for $\mathrm{T}_{1}{ }^{\prime}$ yields the carbon end of the adsorbate binding to two adjacent 5-fold coordinated molybdenum centers (Fig. $3 b$ top), while at $T_{2}$ termination the carbon end binds only with one Mo center. Consequently, the corresponding $\mathrm{E}_{\text {ads }}$ differ substantially, $-3.49 \mathrm{eV}$ for $\mathrm{T}_{1}{ }^{\prime}$ and $-2.71 \mathrm{eV}$ for $\mathrm{T}_{2}$; revealing that $\mathrm{COH}$ prefers adsorption at $\mathrm{T}_{1}{ }^{\prime}$ terminated $\mathrm{MoS}_{2}$ surface over $\mathrm{T}_{2}$. 
Geometry optimizations hydroxy methine, $\mathbf{C H O H}$, at the $\mathrm{MoS}_{2}$ model surface yield for $\mathrm{T}_{1}{ }^{\prime}$ and $\mathrm{T}_{2}$ termination two different local energy minima each where those of lowest total energy for each termination are shown by their equilibrium geometries (Fig. 3c). In both cases the adsorbate is found to bridge two adjacent molybdenum centers with its carbon center which accounts for $\mathrm{E}_{\mathrm{ads}}$ of $-2.60 \mathrm{eV}\left(\mathrm{T}_{1}{ }^{\prime}\right)$ and $-2.61 \mathrm{eV}\left(\mathrm{T}_{2}\right)$ (Table 1a). This indicates very similar adsorbate binding for both surface terminations. The most stable adsorption geometries of the formaldehyde species, $\mathbf{C H}_{\mathbf{2}} \mathbf{O}$, at the two differently terminated $\mathrm{MoS}_{2}$ surfaces (of three local equilibrium geometries found for each termination) are sketched in Fig. $3 \mathrm{~d}$. While the $\mathrm{E}_{\text {ads }}$ at both sites are almost identical, $-0.50 \mathrm{eV}\left(\mathrm{T}_{1}{ }^{\prime}\right)$ and $-0.52 \mathrm{eV}\left(\mathrm{T}_{2}\right)$ (Table 1a), the binding mechanisms are rather different. For $\mathrm{T}_{1}{ }^{\prime}$ termination the $\mathrm{CO}$ part of the adsorbate bridges two adjacent molybdenum centers whereas at $\mathrm{T}_{2}$ terminated surface the molecule binds with its CO part to only one center yielding a 6-fold coordinated Mo species. The calculated $\mathrm{E}_{\text {ads }}$ value for $\mathrm{CH}_{2} \mathrm{O}$ is found to be the smallest amongst all $\mathrm{C}_{1} \mathrm{H}_{\mathrm{x}} \mathrm{O}_{\mathrm{y}}$ species considered. In addition, the adsorbate charge of $\mathrm{CH}_{2} \mathrm{O}$ is very close to zero (Table 1), yielding an almost neutral species. These results are obvious since $\mathrm{CH}_{2} \mathrm{O}$ forms a stable closed-shell molecule interacting more weakly with the substrate compared with the other $\mathrm{C}_{1} \mathrm{H}_{\mathrm{x}} \mathrm{O}_{\mathrm{y}}$ species which represent highly reactive species. Weak adsorptive binding of $\mathrm{CH}_{2} \mathrm{O}$ has also been observed on other substrates like e. g. the $\operatorname{Pt}(111)$ surface [51].

The most stable adsorption geometries of hydroxy methylen, $\mathbf{C H}_{\mathbf{2}} \mathbf{O H}$, at the two $\mathrm{MoS}_{2}$ surfaces (of two local equilibrium geometries found for each termination) are sketched in Fig. 3e. Here the adsorbate binding geometry is rather similar with the case of $\mathrm{CH}_{2} \mathrm{O}$. For $\mathrm{T}_{1}{ }^{\prime}$ termination the $\mathrm{CO}$ part of the adsorbate bridges two adjacent molybdenum centers whereas at $T_{2}$ terminated surface the molecule binds with its CO part to only one center yielding a 6-fold coordinated Mo species. The calculations yield $\mathrm{E}_{\mathrm{ads}}$ of $-1.99 \mathrm{eV}\left(\mathrm{T}_{1}{ }^{\prime}\right)$ and $-1.53 \mathrm{eV}\left(\mathrm{T}_{2}\right)$ (Table 1a), suggesting stronger binding for $\mathrm{T}_{1}{ }^{\prime}$ compared with $\mathrm{T}_{2}$ termination.

Methoxy, $\mathbf{C H}_{3} \mathbf{O}$, stabilizes at $\mathrm{T}_{1}{ }^{\prime}$ and $\mathrm{T}_{2}$ terminated $\mathrm{MoS}_{2}$ surfaces with most favorable adsorption geometries that are similar. Here the oxygen end of the adsorbate binds between two adjacent molybdenum centers (Fig. 3f, two local equilibrium geometries for each termination are found). As for $\mathrm{CH}_{2} \mathrm{OH}$, binding is weaker at $\mathrm{T}_{2}$ compared with $\mathrm{T}_{1}{ }^{\prime}$ terminated surface yielding $\mathrm{E}_{\text {ads }}$ of -3.20 $\mathrm{eV}\left(\mathrm{T}_{1}{ }^{\prime}\right)$ and $-2.67 \mathrm{eV}\left(\mathrm{T}_{2}\right)$, respectively. Adsorption of formate, $\mathbf{H C O O}$, and carbonate, $\mathbf{C O}_{3}$, species, although not appearing in reaction steps (1) and (2a-c), is also considered for completeness. 
Both species result in most stable adsorption geometries with oxygen of the corresponding OCO part bridging two adjacent molybdenum centers of the substrate, independent of the termination (Fig. 4a, b). The $\mathrm{E}_{\mathrm{ads}}$ for HCOO, $-2.95 \mathrm{eV}\left(\mathrm{T}_{1}{ }^{\prime}\right)$ and $-2.90 \mathrm{eV}\left(\mathrm{T}_{2}\right)$, differ only slightly between the terminations while for $\mathrm{CO}_{3}$ the difference between the $\mathrm{E}_{\text {ads }}$ values, $-3.95 \mathrm{eV}\left(\mathrm{T}_{1}{ }^{\prime}\right)$ and $-4.25 \mathrm{eV}\left(\mathrm{T}_{2}\right)$, is larger, suggesting weaker binding for $\mathrm{T}_{1}{ }^{\prime}$ compared with $\mathrm{T}_{2}$ termination. The $\mathrm{E}_{\mathrm{ads}}$ for $\mathrm{CO}_{3}$ is the largest amongst all adsorbates considered in this study. This shows that this adsorbate is very strongly binding with the substrate where ionic contributions become important. The latter is confirmed by the relatively large negative charge of -0.6 to -0.7 calculated for the adsorbate (Table 1 ). Interestingly, the two C-O distances of the OCO part, common to both adsorbates, are not changed by the adsorption (i.e. distance differences are below $0.01 \AA$ ). This suggests that the OCO part is almost inert and cannot be activated easily.

\subsubsection{Adsorbed $\mathrm{C}_{2} \mathrm{H}_{x} \mathrm{O}_{y}$ species}

Geometry optimizations of acetyl, $\mathbf{C H}_{3} \mathbf{C O}$, at the $\mathrm{MoS}_{2}$ model surface yield for $\mathrm{T}_{1}{ }^{\prime}$ and $\mathrm{T}_{2}$ termination two different local energy minima each where those of lowest total energy for each termination are shown by their equilibrium geometries in Fig. 4c. In both cases the $\mathrm{CO}$ part of the adsorbate is found to bridge two adjacent molybdenum centers resulting in $\mathrm{E}_{\text {ads }}$ of $-1.98 \mathrm{eV}\left(\mathrm{T}_{1}{ }^{\prime}\right)$ and $-2.03 \mathrm{eV}\left(\mathrm{T}_{2}\right)$ (Table $\left.1 \mathrm{~b}\right)$, indicating very similar adsorbate binding for both surface terminations. For both terminations the $\mathrm{C}-\mathrm{O}$ distance of free $\mathrm{CH}_{3} \mathrm{CO}$ is increased from 1.19 to $1.25 \AA$ in the adsorbed state which can be understood as an adsorption-induced activation of the C-O bond in $\mathrm{CH}_{3} \mathrm{CO}$. The most stable adsorption geometries of acetaldehyde, $\mathbf{C H}_{3} \mathbf{C H O}$, at the two differently terminated $\mathrm{MoS}_{2}$ surfaces are shown in Fig. 4d. Obviously, the resulting binding scheme is similar in both cases: $\mathrm{CH}_{3} \mathrm{CHO}$ binds with its oxygen tail at one molybdenum center. This yields quite small $\mathrm{E}_{\text {ads }}$ of $-0.40 \mathrm{eV}\left(\mathrm{T}_{1}{ }^{\prime}\right)$ and $-0.34 \mathrm{eV}\left(\mathrm{T}_{2}\right)$ (Table $1 \mathrm{~b}$ ), which are the smallest amongst all $\mathrm{C}_{2} \mathrm{H}_{\mathrm{x}} \mathrm{O}_{\mathrm{y}}$ species considered in the present work. This is, in analogy with the previous result for $\mathrm{CH}_{2} \mathrm{O}$, explained by $\mathrm{CH}_{3} \mathrm{CHO}$ forming a stable closed-shell molecule which, therefore, interacts weakly with the substrate. The $\mathrm{C}-\mathrm{O}$ distance in free $\mathrm{CH}_{3} \mathrm{CHO}$ is increased by only $0.02 \AA$ due to adsorption at $\mathrm{T}_{1}{ }^{\prime}$ or $\mathrm{T}_{2}$ terminated surface. This can be understood, analogous to the findings for $\mathrm{COH}$, by the fact that $\mathrm{CH}_{3} \mathrm{CHO}$ binds only with its carbon end to one Mo substrate atom (Fig. 4d), influencing the 
C-O bond only little. $\mathrm{CH}_{3} \mathrm{CHO}$ species has been identified by temperature programmed desorption (TPD) measurements in $\mathrm{CO}$ hydrogenation on $\mathrm{Co} / \mathrm{Cu}$-based catalyst $[18,19]$.

Ethoxy, $\mathbf{C H}_{3} \mathbf{C H}_{2} \mathbf{O}$, stabilizes at $\mathrm{T}_{1}{ }^{\prime}$ and $\mathrm{T}_{2}$ terminated $\mathrm{MoS}_{2}$ surfaces with most favorable adsorption geometries, are also similar. The oxygen tail of the adsorbate binds in both cases between two adjacent molybdenum centers (Fig. 4e). Here binding is stronger at $\mathrm{T}_{1}{ }^{\prime}$ compared with $\mathrm{T}_{2}$ terminated surface with $\mathrm{E}_{\mathrm{ads}}$ of $-3.16 \mathrm{eV}\left(\mathrm{T}_{1}^{\prime}\right)$ and $-2.67 \mathrm{eV}\left(\mathrm{T}_{2}\right)$, respectively. Finally, acetate, $\mathbf{C H}_{3} \mathbf{C O O}$, leads to most stable adsorption geometries with oxygen of the corresponding OCO part bridging two adjacent molybdenum centers of the substrate, independent of the termination (Fig. 4f). The $\mathrm{E}_{\mathrm{ads}}$ amount to $-2.87 \mathrm{eV}\left(\mathrm{T}_{1}^{\prime}\right)$ and $-2.73 \mathrm{eV}\left(\mathrm{T}_{2}\right)$, respectively, which yields a slight energetic preference for $\mathrm{T}_{1}{ }^{\prime}$ termination of the $\mathrm{MoS}_{2}$ surface. As for $\mathrm{HCOO}$ and $\mathrm{CO}_{3}$ discussed above, the two $\mathrm{C}-\mathrm{O}$ distances of the $\mathrm{OCO}$ part of $\mathrm{CH}_{3} \mathrm{COO}$ are not affected by adsorption suggesting that the OCO part of the adsorbate cannot be activated easily.

\subsubsection{Adsorbed $\mathrm{CH}_{\mathrm{x}}$ and $\mathrm{OH}_{\mathrm{x}}$ species}

Atomic carbon was found to adsorb at both the $\mathrm{T}_{1}{ }^{\prime}$ and $\mathrm{T}_{2}$ terminated $\mathrm{MoS}_{2}$ surfaces bridging two adjacent molybdenum centers and coupling with the nearest sulfur center, see Fig. 5a, and forming fairly strong bonds as indicated by $\mathrm{E}_{\mathrm{ads}}$ values of $-5.40\left(\mathrm{~T}_{1}{ }^{\prime}\right)$ and $-5.56 \mathrm{eV}\left(\mathrm{T}_{2}\right)$. Both $\mathbf{C H}$ and $\mathbf{C H}_{2}$ adsorbates exhibit the most stable adsorption geometries also with carbon bridging two adjacent molybdenum sites by strong adsorption bonds, see Fig. 5b, c. In addition, CH couples with the nearest sulfur center, analogous to atomic carbon, whereas $\mathrm{CH}_{2}$ binds only with molybdenum centers. The computed adsorption energies $\mathrm{E}_{\mathrm{ads}}$ are $-5.73\left(\mathrm{~T}_{1}{ }^{\prime}\right)$ and $-6.03 \mathrm{eV}\left(\mathrm{T}_{2}\right)$ for $\mathrm{CH}$ while they amount to $-4.26\left(\mathrm{~T}_{1}{ }^{\prime}\right)$ and $-4.41 \mathrm{eV}\left(\mathrm{T}_{2}\right)$ for $\mathrm{CH}_{2}$. The most stable adsorbate geometry for $\mathbf{C H}_{3}$ yields the carbon end of the adsorbate binding to only one molybdenum center such that the carbon is 4-fold coordinated in a distorted tetrahedral environment, see Fig. 5d. In this geometry the adsorption bond is relatively weak leading to $E_{a d s}$ values of $-1.71\left(T_{1}{ }^{\prime}\right)$ and $-1.59 \mathrm{eV}\left(\mathrm{T}_{2}\right)$, respectively. Finally, atomic oxygen and $\mathbf{O H}$ are also found to stabilize at both the $\mathrm{T}_{1}{ }^{\prime}$ and $\mathrm{T}_{2}$ terminated $\mathrm{MoS}_{2}$ surfaces where the oxygen bridges two adjacent molybdenum centers. The computed adsorption energies $E_{a d s}$ amount to $-5.43\left(\mathrm{~T}_{1}{ }^{\prime}\right)$ and $-5.17 \mathrm{eV}\left(\mathrm{T}_{2}\right)$, respectively, for atomic oxygen and to -3.86 $\left(\mathrm{T}_{1}{ }^{\prime}\right)$ and $-3.49 \mathrm{eV}\left(\mathrm{T}_{2}\right)$ for $\mathrm{OH}$. 


\subsection{Vibrational properties of reaction intermediates}

Koizumi et al. [8] examined $\mathrm{CO}$ hydrogenation at unpromoted $\mathrm{MoS}_{2} / \gamma-\mathrm{Al}_{2} \mathrm{O}_{3}$ catalysts using in situ DRIFT spectroscopy and observed six different peaks at $2060 \mathrm{~cm}^{-1}, 2010 \mathrm{~cm}^{-1}, 1590 \mathrm{~cm}^{-1}$, $1470 \mathrm{~cm}^{-1}, 1420 \mathrm{~cm}^{-1}$, and $1385 \mathrm{~cm}^{-1}$. The peaks at $2060 \mathrm{~cm}^{-1}$ and $2010 \mathrm{~cm}^{-1}$ were attributed to CO adsorption and also confirmed by separate experiments and calculations [32]. Here we restrict ourselves to the peak region between 1280 and $1600 \mathrm{~cm}^{-1}$ ignoring $\mathrm{CH}_{\mathrm{x}}$ and $\mathrm{OH}$ vibrations which lie outside this frequency range. All the other reaction intermediates are examined in their vibrational behavior by corresponding normal mode analyses in the adsorbed state. Characteristic frequencies for each adsorbate at the $\mathrm{T}_{1}{ }^{\prime}$ and $\mathrm{T}_{2}$ terminated $\mathrm{MoS}_{2}(10-10)$ surfaces are listed in Table 2 where the calculated values are restricted to a range between 1280 and $1600 \mathrm{~cm}^{-1}$ reflecting the experimental range considered in the DRIFT experiments for an $\mathrm{MoS}_{2} / \gamma-\mathrm{Al}_{2} \mathrm{O}_{3}$ catalyst [8]. In addition, Table 3 compares the computed vibrational frequencies of the adsorbates with the experimental DRIFT data [8] where vibrations of the different adsorbates in a given frequency range are combined for the comparison with experimental peaks (given by their peak center). The comparison confirms most of the experimental assignments by theory but yield also additional information from the calculations.

The calculations yield vibrations for the four adsorbates $\mathrm{CHOH}, \mathrm{COH}, \mathrm{CHO}$ and $\mathrm{CH}_{3} \mathrm{CO}$ in the frequency range between 1286 and $1336 \mathrm{~cm}^{-1}$ which could explain the rather weak structure in the experimental infrared spectrum slightly above $1300 \mathrm{~cm}^{-1}$. Further, the experimental spectrum shows two broadened peaks with additional structure between 1370 and $1400 \mathrm{~cm}^{-1}$ where the peak at lower frequency near $1385 \mathrm{~cm}^{-1}$ was assigned [8] to formate, $\mathrm{HCOO}$, while the higher peak was not identified. In the calculations the frequency region between 1349 and $1403 \mathrm{~cm}^{-1}$ accommodates vibrational excitations from five different adsorbates listed in Table 3. This includes HCOO at 1374 $\left(\mathrm{T}_{1}^{\prime}\right)$ and $1372 \mathrm{~cm}^{-1}\left(\mathrm{~T}_{2}\right)$ (Table 2), which is consistent with the previous interpretation of the experimental lower peak. In addition, the higher experimental peak near $1395 \mathrm{~cm}^{-1}$ is assigned in the calculations to a combination of the four $\mathrm{CH}_{3}$ containing adsorbates $\mathrm{CH}_{3} \mathrm{CO}, \mathrm{CH}_{3} \mathrm{CHO}, \mathrm{CH}_{3} \mathrm{COO}$ and $\mathrm{CH}_{3} \mathrm{CH}_{2} \mathrm{O}$ where the relative importance of the difference species can be determined only in separate experiments.

There is an additional structure between 1415 and $1440 \mathrm{~cm}^{-1}$ in the experimental spectrum 
where lower end at $1420 \mathrm{~cm}^{-1}$ was assigned [8] also to HCOO. The latter cannot be confirmed by the present calculations. The experimental frequency range between 1413 and $1443 \mathrm{~cm}^{-1}$ is described in the calculations by vibrations of the six $\mathrm{CH}_{2}$ and $\mathrm{CH}_{3}$ containing adsorbates $\mathrm{CH}_{2} \mathrm{O}$, $\mathrm{CH}_{2} \mathrm{OH}, \mathrm{CH}_{3} \mathrm{O}, \mathrm{CH}_{3} \mathrm{CO}, \mathrm{CH}_{3} \mathrm{CHO}$ and $\mathrm{CH}_{3} \mathrm{COO}$ (Table 3), with no contribution from formate. The peak region near $1470 \mathrm{~cm}^{-1}$ in the experimental spectrum was assigned [8] to vibrations of the three adsorbates $\mathrm{CH}_{3} \mathrm{COO}, \mathrm{CH}_{3} \mathrm{O}$ and $\mathrm{CO}_{3}$. This is only partly compatible with our computed results where the experimental frequency range between 1447 and $1488 \mathrm{~cm}^{-1}$ is covered by vibrations of the six adsorbates $\mathrm{CH}_{3} \mathrm{COO}, \mathrm{CH}_{3} \mathrm{O}, \mathrm{CHO}, \mathrm{COH}, \mathrm{CH}_{3} \mathrm{CO}$ and $\mathrm{CH}_{3} \mathrm{CH}_{2} \mathrm{O}$ (Table 3), with $\mathrm{CO}_{3}$ missing. Instead, vibrations of adsorbed $\mathrm{CO}_{3}$ are calculated to yield frequencies of $1747 \mathrm{~cm}^{-1}\left(\mathrm{~T}_{1}{ }^{\prime}\right)$ and $1744 \mathrm{~cm}^{-1}\left(\mathrm{~T}_{2}\right)$ (Table 2), where there is no clear structure in the experimental spectrum. This may indicate that carbonate species do not appear in the $\mathrm{CO}$ hydrogenation experiment under the conditions described in Ref. [8] (Note that vibrations of adsorbed bridging $\mathrm{CO}_{3}$ on Pt catalysts have been measured to yield $1725 \mathrm{~cm}^{-1}$ [52].) Finally, the experimental spectrum shows a broad asymmetric peak between 1560 and $1600 \mathrm{~cm}^{-1}$ where a frequency of $1590 \mathrm{~cm}^{-1}$ was assigned [8] to vibrations of the HCOO. This is confirmed by the calculations which yield HCOO vibrations at 1535 and 1562 $\mathrm{cm}^{-1}$ giving further evidence that the formate adsorbate appears in the CO hydrogenation experiment described in Ref. [8].

\subsection{CO hydrogenation at the $\mathrm{MoS}_{2}$ surface}

CO hydrogenation on pure $\mathrm{MoS}_{2}$ is found to yield mainly $\mathrm{C}_{1}$ type products. Therefore, we focus in the following on reaction steps producing $\mathrm{C}_{1}$ species. Corresponding reaction energies, $\Delta \mathrm{E}_{\text {coad }}$ and $\Delta \mathrm{E}_{\mathrm{sep}}$, as well as activation energies $\mathrm{E}_{\mathrm{a}}$, involving all reaction intermediates discussed in Sec. 3.1 have been evaluated and are listed in Table 4. Figs. 6, 7 sketch calculated geometric structures of the optimized reactants, transition states, and products at the $T_{1}{ }^{\prime}$ and $T_{2}$ terminated $M_{0} S_{2}$ surfaces for the most favorable reaction paths each. Further, Fig. 8 shows corresponding energetic reaction schemes based on the results of Table 4 where the most favorable reaction path is highlighted by thick lines. Overall, the results in Table 4 show that reaction energies starting from completely separated surface species, $\Delta \mathrm{E}_{\mathrm{sep}}$ of definition (4), and from coadsorbed nearby species, $\Delta \mathrm{E}_{\mathrm{coad}}$ of definition (5), yield the same trends. (The same conclusions have been arrived at in studies on the 
dehydrogenation of methanol over Pt (111) surface [51].) They quantify thermodynamic reaction properties and are used in the following to characterize relative thermodynamic reaction probabilities (only $\Delta \mathrm{E}_{\text {coad }}$ values will be mentioned). In contrast, the energy barriers $\mathrm{E}_{\mathrm{a}}$, given in Table 4 and discussed in the following, characterize kinetic probabilities of corresponding reactions. It should be emphasized that our reaction studies are always based on Langmuir-Hinshelwood [53] type reaction schemes (which may also be connected with hydrogen spillover [28,31]) where only adsorbed species are considered and additional adsorption/desorption processes are ignored.

\subsubsection{Initial reaction of $\mathrm{CO}$ with hydrogen}

Fig. 6a shows that coadsorption of $\mathrm{CO}$ and $\mathrm{H}$ at the $\mathrm{T}_{1}{ }^{\prime}$ terminated $\mathrm{MoS}_{2}$ edge yields $\mathrm{CO}$ adsorbed near the 5-fold Mo site with $\mathrm{H}$ at the nearby top S site. Starting from this coadsorption, CHO formation is more favorable than $\mathrm{COH}$ both kinetically $\left(\mathrm{E}_{\mathrm{a}}=1.45 \mathrm{vs} .1 .75 \mathrm{eV}\right)$ and thermodynamically $\left(\Delta \mathrm{E}_{\text {coad }}=0.36\right.$ vs. $\left.0.79 \mathrm{eV}\right)$, see Table 4 . Subsequent dissociation of adsorbed CHO to yield $\mathrm{CH}$ and $\mathrm{O}$ is connected with a barrier of $1.46 \mathrm{eV}$ and is endothermic by $0.80 \mathrm{eV}$. Obviously, $\mathrm{CHO}$ will be the first intermediate of CO reacting with hydrogen. The same qualitative results, with, however, larger barriers are found for the $\mathrm{T}_{2}$ terminated $\mathrm{MoS}_{2}$ edge, see Fig. $7 \mathrm{a}$.

The $\mathrm{CHO}$ adsorbate may react with another hydrogen adsorbate to form $\mathrm{CH}_{2} \mathrm{O}$ or $\mathrm{CHOH}$ surface species. The coadsorbate geometry at the $\mathrm{T}_{1}{ }^{\prime}$ terminated $\mathrm{MoS}_{2}$ edge yields $\mathrm{CHO}$ assuming the

geometry of the previous hydrogenation reaction and the hydrogen stabilizing at a nearby top S site, either close to the carbon or close to the oxygen of the CHO adsorbate. While two coadsorbate configurations are close in energy the first geometry leads to $\mathrm{CH}_{2} \mathrm{O}$ as a reaction product as shown in Fig. $6 \mathrm{~b}$ while the latter results in $\mathrm{CHOH}$. Here $\mathrm{CH}_{2} \mathrm{O}$ formation is more favorable than $\mathrm{CHOH}$ both kinetically $\left(\mathrm{E}_{\mathrm{a}}=0.79\right.$ vs. $\left.1.06 \mathrm{eV}\right)$ and thermodynamically $\left(\Delta \mathrm{E}_{\mathrm{coad}}=-0.48 \mathrm{vs} .0 .00 \mathrm{eV}\right)$. Subsequent dissociation of adsorbed $\mathrm{CH}_{2} \mathrm{O}$ into $\mathrm{CH}_{2}$ and $\mathrm{O}$ is connected with a barrier of $1.47 \mathrm{eV}$ and is exothermic by $-0.28 \mathrm{eV}$. The same qualitative results, with, however, larger barriers are found for the $\mathrm{T}_{2}$ terminated $\mathrm{MoS}_{2}$ edge, see Fig. $7 \mathrm{~b}$. Thus the second intermediate for CO hydrogenation will be $\mathrm{CH}_{2} \mathrm{O}$.

The $\mathrm{CH}_{2} \mathrm{O}$ adsorbate can react with another hydrogen adsorbate to form $\mathrm{CH}_{2} \mathrm{OH}$ or $\mathrm{CH}_{3} \mathrm{O}$ 
surface species. As before the coadsorbate geometry at the $\mathrm{T}_{1}$ ' terminated $\mathrm{MoS}_{2}$ edge allows for hydrogen stabilizing at a top $\mathrm{S}$ site, either close to the carbon or close to the oxygen of the $\mathrm{CH}_{2} \mathrm{O}$ adsorbate where the two configurations are close in energy. Here the first geometry leads to $\mathrm{CH}_{3} \mathrm{O}$ as a reaction product as illustrated in Fig. 6c while the latter results in $\mathrm{CH}_{2} \mathrm{OH}$. The numerical results

in Table 4 show that both $\mathrm{CH}_{2} \mathrm{OH}$ and $\mathrm{CH}_{3} \mathrm{O}$ formation are favorable thermodynamically $\left(\Delta \mathrm{E}_{\text {coad }}=\right.$ -0.52 vs. $-1.36 \mathrm{eV})$ where the former is kinetically more favorable $\left(\mathrm{E}_{\mathrm{a}}=0.88\right.$ vs. $\left.1.60 \mathrm{eV}\right)$. Subsequent dissociation of adsorbed $\mathrm{CH}_{2} \mathrm{OH}$ into $\mathrm{CH}_{2}$ and $\mathrm{OH}$ is connected with a barrier of $0.95 \mathrm{eV}$ and is exothermic by $-0.29 \mathrm{eV}$. On the other hand, $\mathrm{CH}_{3} \mathrm{O}$ dissociation into surface $\mathrm{CH}_{3}$ and $\mathrm{O}$ is neither kinetically $\left(\mathrm{E}_{\mathrm{a}}=2.59 \mathrm{eV}\right)$ nor thermodynamically feasible $\left(\Delta \mathrm{E}_{\mathrm{coad}}=1.35 \mathrm{eV}\right)$. Altogether, the dissociation of adsorbed $\mathrm{CH}_{2} \mathrm{OH}$ into $\mathrm{CH}_{2}$ and $\mathrm{OH}$ is more likely to happen. As another competing step, $\mathrm{CH}_{2} \mathrm{OH}$ may react with surface hydrogen to form $\mathrm{CH}_{3} \mathrm{OH}$. However, our calculations show that the hydrogenation of $\mathrm{CH}_{2} \mathrm{OH}$, while gaining more energy than the dissociation, is less likely to occur due to its reaction barrier, $1.26 \mathrm{eV}$, see Table 4, which is higher than that of the dissociation process, $0.95 \mathrm{eV}$. Qualitatively similar results are found for the $\mathrm{T}_{2}$ terminated $\mathrm{MoS}_{2}$ edge, see Fig. 7c. Thus the third intermediate for $\mathrm{CO}$ hydrogenation will be $\mathrm{CH}_{2} \mathrm{OH}$ followed by cleavage of its $\mathrm{C}-\mathrm{O}$ bond.

\subsubsection{Reaction of $\mathrm{CH}_{2}$ with hydrogen}

As discussed above, $\mathrm{CO}$ hydrogenation at the $\mathrm{MoS}_{2}(10-10)$ surface will yield, amongst other products, surface $\mathrm{CH}_{2}$. This species can react further with adsorbed hydrogen yielding $\mathrm{CH}_{4}$ in two reaction steps. The coadsorbate geometry at the $\mathrm{T}_{1}$ ' edge yields $\mathrm{CH}_{2}$ bridging two Mo centers and the hydrogen stabilizing at a nearby top $\mathrm{S}$ site. This leads to adsorbed $\mathrm{CH}_{3}$ as a reaction product as shown in Fig. $6 \mathrm{~d}$ where the reaction is exothermic $\left(\Delta \mathrm{E}_{\mathrm{coad}}=-0.20 \mathrm{eV}\right)$ and connected with a moderate barrier of $\mathrm{E}_{\mathrm{a}}=0.97 \mathrm{eV}$. In a subsequent reaction the adsorbed $\mathrm{CH}_{3}$ can combine with another hydrogen to produce $\mathrm{CH}_{4}$ where the reaction is strongly exothermic $\left(\Delta \mathrm{E}_{\text {coad }}=-1.26 \mathrm{eV}\right)$ and connected with a barrier of only $\mathrm{E}_{\mathrm{a}}=0.53 \mathrm{eV}$. For comparison, adsorbed $\mathrm{CH}_{3}$ reacting with surface $\mathrm{OH}$ to form $\mathrm{CH}_{3} \mathrm{OH}$ is found to yield a rather high barrier, $\mathrm{E}_{\mathrm{a}}=1.68 \mathrm{eV}$, and is much less exothermic, $\Delta \mathrm{E}_{\text {coad }}=-0.38 \mathrm{eV}$, than $\mathrm{CH}_{4}$ formation. The same qualitative results are found for the $\mathrm{T}_{2}$ terminated $\mathrm{MoS}_{2}$ edge, see Fig. 7d. Altogether, the calculations show that $\mathrm{CH}_{2}$ reacting with hydrogen at the $\mathrm{MoS}_{2}(10-10)$ surface to form adsorbed $\mathrm{CH}_{4}$ is a very likely process. The resulting $\mathrm{CH}_{4}$ species can 
be assumed to bind very weakly with the surface and may easily desorb.

\subsubsection{Optimized reaction paths}

Fig. 8 shows energetic reaction schemes for sequential CO hydrogenation at the $\mathrm{MoS}_{2}(10-10)$ surface for both $\mathrm{T}_{1}$ ' (Fig. 8a) and $\mathrm{T}_{2}$ edges (Fig. 8b) which consider all reaction steps discussed above where reaction intermediates and products are assumed in their adsorbed states at the surface resulting in Langmuir-Hinshelwood type reactions. This yields optimized reaction paths combining energetically lowest reaction intermediates and lowest reaction barriers which are highlighted by thick lines in Fig.8. Obviously, the most favorable reaction path is qualitatively the same for both terminations and involves $\mathrm{C}_{1}$ type surface species in the sequence

$$
\mathrm{CO} \rightarrow \mathrm{CHO} \rightarrow \mathrm{CH}_{2} \mathrm{O} \rightarrow \mathrm{CH}_{2} \mathrm{OH} \rightarrow \mathrm{CH}_{2} \rightarrow \mathrm{CH}_{3} \rightarrow \mathrm{CH}_{4}
$$

This pathway is consistent with experimental findings [8] but disagrees in some details with recent theoretical studies [35] where the $\mathrm{MoS}_{2}(10-10)$ surface was modeled with pure Mo metal and pure

sulfur termination. The authors find for the pure Mo metal termination that both adsorbed $\mathrm{CHO}$ and $\mathrm{CH}_{2} \mathrm{O}$ species can dissociate breaking its $\mathrm{C}-\mathrm{O}$ bond in an exothermic reaction with a rather low barrier. (The corresponding $\mathrm{E}_{\mathrm{a}}$ and $\Delta \mathrm{E}_{\mathrm{coad}}$ values are included in Table 4.) This misses the reaction intermediates $\mathrm{CH}_{2} \mathrm{OH}$ and $\mathrm{CH}_{3} \mathrm{O}$ found in the present study and leads to a shortened reaction path which involves $\mathrm{C}_{1}$ type surface species in the sequence

$$
\mathrm{CO} \rightarrow \mathrm{CHO} \rightarrow \mathrm{CH}_{2} \mathrm{O} \rightarrow \mathrm{CH}_{3} \rightarrow \mathrm{CH}_{4}
$$

The discrepancy is most likely due to the different $\mathrm{MoS}_{2}$ surface terminations considered Ref. [35] as compared to the present study where the present surface terminations are believed to be more realistic. It should be noted that on both the sulfur covered and the pure metal surface, formyl (CHO) is the first intermediate for the activation of CO. Surface formyl is also found as the most important intermediate in Fischer-Tropsch process on metal surfaces [54] and in the reforming of $\mathrm{CO}_{2}$ to methane on Ni surfaces [55]. 


\section{CONCLUSIONS}

The present theoretical studies give a clear account of the adsorption of reaction intermediates appearing during $\mathrm{CO}$ hydrogenation at the sulfur covered $\mathrm{MoS}_{2}(10-10)$ surface as well as of the elementary reaction steps. Periodic density functional theory calculations using the generalized gradient corrected functional due to Perdew and Wang [40,41] provide adsorption energies of the different adsorbates. The results, considering two different surface terminations of $\mathrm{MoS}_{2}(10-10)$, show highly localized strong adsorbate - molybdenum interaction for all (slightly charged) adsorbates with adsorption energies ranging between $-1.6 \mathrm{eV}$ and $-6.0 \mathrm{eV}$. Adsorption of the (neutral) molecular reaction intermediates $\mathrm{CH}_{2} \mathrm{O}$ and $\mathrm{CH}_{3} \mathrm{CHO}$ is found to be much weaker yielding adsorption energies $\mathrm{E}_{\mathrm{ads}}$ of $-0.5 \mathrm{eV}$ and $-0.4 \mathrm{eV}$, respectively.

The reaction intermediates $\mathrm{C}_{1} \mathrm{H}_{\mathrm{x}} \mathrm{O}_{\mathrm{y}}$ and $\mathrm{C}_{2} \mathrm{H}_{\mathrm{x}} \mathrm{O}_{\mathrm{y}}$ are examined in their vibrational behavior by corresponding normal mode analyses in the adsorbed state. A comparison of the computed vibrational frequencies with experimental data from measurements applying infrared (DRIFT) spectroscopy to a $\mathrm{MoS}_{2} / \gamma-\mathrm{Al}_{2} \mathrm{O}_{3}$ catalyst [8] confirms most of the experimental assignments but yields also new information. In particular, the frequency analyses give clear evidence that formate species, $\mathrm{HCOO}$, appears in the $\mathrm{CO}$ hydrogenation experiment under the conditions described in Ref. [8] while they suggest that carbonate species, $\mathrm{CO}_{3}$, may not participate in the reaction. More detailed information can be obtained only after experimental spectra with higher resolution have been carried out in $\mathrm{CO}$ hydrogenation experiments under well defined conditions where additional measurements are performed to identify possible reaction intermediates.

Further, systematic density-functional theory studies on possible reaction steps during CO hydrogenation at the sulfur covered $\mathrm{MoS}_{2}(10-10)$ surface are used to identify optimized reaction paths which are found to involve $C_{1}$ type surface species in the sequence

$$
\mathrm{CO} \rightarrow \mathrm{CHO} \rightarrow \mathrm{CH}_{2} \mathrm{O} \rightarrow \mathrm{CH}_{2} \mathrm{OH} \rightarrow \mathrm{CH}_{2} \rightarrow \mathrm{CH}_{3} \rightarrow \mathrm{CH}_{4} .
$$

In particular, the dissociation of adsorbed $\mathrm{CH}_{2} \mathrm{OH}$ results in $\mathrm{CH}_{2}$ and $\mathrm{OH}$ products where $\mathrm{CH}_{2}$ can react further to form $\mathrm{CH}_{4}$. In addition, surface $\mathrm{OH}$ formed during the reactions may dissociate into adsorbed $\mathrm{O}$ and $\mathrm{H}$ or react with hydrogen to form water species undergoing a water-gas-shift reaction. These processes merit a separate discussion which goes beyond the scope of the present work 
and will be considered in a subsequent study. The above pathway is consistent with experimental findings [8] but disagrees in some details with recent theoretical studies [35] where the $\mathrm{MoS}_{2}(10-10)$ surface was modeled with pure Mo metal and pure sulfur termination. The disagreement is most likely due to differences in the $\mathrm{MoS}_{2}$ surface terminations considered in the studies. The present results cannot confirm the existence of formate, $\mathrm{HCOO}$, intermediates found in the experiment [8]. This may be explained by the fact that in $\mathrm{CO}$ hydrogenation experiments on $\mathrm{MoS}_{2}$ catalysts there is always a high probability of the water-gas shift reaction, $\mathrm{CO}+\mathrm{H}_{2} \mathrm{O} \rightarrow \mathrm{H}_{2}+\mathrm{CO}_{2}$, occurring in parallel. The latter is bond to produce formate as a reaction intermediate [56-60] which was discussed elsewhere [61].

\section{ACKNOWLEDGEMENTS}

This work was partly supported by the National Natural Science Foundation of China (No. 20590363 and 20876163), by the State Key Fundamental Research Program (No. 2007CB216401), and by the Deutsche Forschungsgemeinschaft (DFG) through its Collaborative Research Center SFB 546 (Transition metal oxide aggregates). One of the authors (X. S.) acknowledges financial support by the Max-Planck Society. We thank Jia Hu, Wenjuan Zhang and Lili Bao in our group for technical support. 
Table 1. Adsorption energies $\mathrm{E}_{\mathrm{ads}}$ ( in $\mathrm{eV}$ ) and adsorbate charges $q$ (in atomic units) of all reaction intermediates at the $\operatorname{MoS}_{2}(10-10)$ surface considered in this work. The data are listed for both the $\mathrm{T}_{1}{ }^{\prime}$ and $\mathrm{T}_{2}$ termination. Corresponding adsorption geometries are shown in Figs. 3,4 .

\begin{tabular}{|c|c|c|}
\hline & $\mathrm{E}_{\mathrm{ads}}\left(\mathrm{T}_{1}^{\prime}\right) / \mathrm{E}_{\mathrm{ads}}\left(\mathrm{T}_{2}\right)$ & $q\left(\mathrm{~T}_{1}^{\prime}\right) / q\left(\mathrm{~T}_{2}\right)$ \\
\hline \multicolumn{3}{|c|}{$\mathrm{C}_{1} \mathrm{H}_{\mathrm{x}} \mathrm{O}_{\mathrm{y}}$ and $\mathrm{CO}_{3}$ species } \\
\hline $\mathrm{CHO}$ & $-2.01 /-1.98$ & $0.11 / 0.14$ \\
\hline $\mathrm{COH}$ & $-3.49 /-2.71$ & $0.22 / 0.44$ \\
\hline $\mathrm{CHOH}$ & $-2.60 /-2.61$ & $0.20 / 0.16$ \\
\hline $\mathrm{CH}_{2} \mathrm{O}$ & $-0.50 /-0.52$ & $-0.06 /-0.01$ \\
\hline $\mathrm{CH}_{2} \mathrm{OH}$ & $-1.99 /-1.53$ & $0.17 / 0.17$ \\
\hline $\mathrm{CH}_{3} \mathrm{O}$ & $-3.20 /-2.67$ & $-0.20 /-0.18$ \\
\hline $\mathrm{HCOO}$ & $-2.95 /-2.90$ & $-0.21 /-0.23$ \\
\hline $\mathrm{CO}_{3}$ & $-3.95 /-4.25$ & $-0.62 /-0.67$ \\
\hline \multicolumn{3}{|c|}{$\mathrm{C}_{2} \mathrm{H}_{\mathrm{x}} \mathrm{O}_{\mathrm{y}}$ species } \\
\hline $\mathrm{CH}_{3} \mathrm{CO}$ & $-1.98 /-2.03$ & $0.18 / 0.18$ \\
\hline $\mathrm{CH}_{3} \mathrm{CHO}$ & $-0.40 /-0.34$ & $0.23 / 0.21$ \\
\hline $\mathrm{CH}_{3} \mathrm{CH}_{2} \mathrm{O}$ & $-3.16 /-2.67$ & $-0.16 /-0.16$ \\
\hline $\mathrm{CH}_{3} \mathrm{COO}$ & $-2.87 /-2.73$ & $-0.16 /-0.18$ \\
\hline \multicolumn{3}{|c|}{$\mathrm{CH}_{\mathrm{x}}$ species } \\
\hline $\mathrm{C}$ & $-5.40 /-5.56$ & $0.07 / 0.09$ \\
\hline $\mathrm{CH}$ & $-5.73 /-6.03$ & $0.10 / 0.10$ \\
\hline $\mathrm{CH}_{2}$ & $-4.26 /-4.41$ & $0.10 / 0.15$ \\
\hline $\mathrm{CH}_{3}$ & $-1.71 /-1.59$ & $0.24 / 0.29$ \\
\hline
\end{tabular}


Table 2. Vibrational frequencies $v\left(\right.$ in $\mathrm{cm}^{-1}$ ) of all reaction intermediates at the $\mathrm{MoS}_{2}(10-10)$ surface considered in this work. The data are listed for both the $\mathrm{T}_{1}{ }^{\prime}$ and $\mathrm{T}_{2}$ termination. The corresponding adsorption geometries are shown in Figs. 3, 4.

\begin{tabular}{ccc}
\hline & $v\left(\mathrm{~T}_{1}{ }^{\prime}\right)$ & $v\left(\mathrm{~T}_{2}\right)$ \\
\hline $\mathrm{CHO}$ & 1336,1488 & 1310,1483 \\
$\mathrm{COH}$ & 1298 & 1468 \\
$\mathrm{CHOH}$ & 1286 & 1317 \\
$\mathrm{CH}_{2} \mathrm{O}$ & 1418 & 1422 \\
$\mathrm{CH}_{2} \mathrm{OH}$ & 1424 & 1437 \\
$\mathrm{CH}_{3} \mathrm{O}$ & $1421,1440,1465$ & $1420,1443,1455$ \\
$\mathrm{HCOO}_{\mathrm{CO}}$ & $1355,1374,1535$ & $1358,1372,1562$ \\
$\mathrm{CH}_{3} \mathrm{CO}$ & 1747 & 1744 \\
& $1327,1386,1434$, & $1329,1419,1450$, \\
$\mathrm{CH}_{3} \mathrm{CHO}$ & 1467 & 1517 \\
& $1349,1391,1423$, & $1373,138,1431$, \\
$\mathrm{CH}_{3} \mathrm{CH} O$ & $1373,1392,1454$, & $1357,1381,1450$, \\
$\mathrm{CH}_{3} \mathrm{COO}$ & 1466,1476 & 1458,1485 \\
& $1379,1413,1439$, & $1456,1403,1442,1531$ \\
\hline
\end{tabular}


Table 3. Comparison of the computed vibrational frequencies $v\left(\right.$ in $\left.\mathrm{cm}^{-1}\right)$ of reaction intermediates adsorbed at the $\mathrm{MoS}_{2}$ (10-10) surface with experimental data from DRIFT spectroscopy for $\mathrm{CO}$ hydrogenation at the unpromoted $\mathrm{MoS}_{2} / \gamma-\mathrm{Al}_{2} \mathrm{O}_{3}$ catalyst [8].

\begin{tabular}{|c|c|c|c|}
\hline \multicolumn{2}{|l|}{ Theory } & \multicolumn{2}{|c|}{ Experiment } \\
\hline$v\left[\mathrm{~cm}^{-1}\right]$ & Assignment & $v$ & Assignment \\
\hline$[1286,1336]$ & $\mathrm{CHOH}, \mathrm{COH}\left(\mathrm{T}_{1}{ }^{\prime}\right), \mathrm{CHO}, \mathrm{CH}_{3} \mathrm{CO}$ & -- & -- \\
\hline$[1349,1403]$ & $\begin{array}{l}\mathrm{HCOO}, \mathrm{CH}_{3} \mathrm{CO}\left(\mathrm{T}_{1}^{\prime}\right), \mathrm{CH}_{3} \mathrm{CHO} \\
\mathrm{CH}_{3} \mathrm{COO}, \mathrm{CH}_{3} \mathrm{CH}_{2} \mathrm{O}\end{array}$ & 1385 & $\mathrm{HCOO}$ \\
\hline$[1413,1443]$ & $\begin{array}{l}\mathrm{CH}_{2} \mathrm{O}, \mathrm{CH}_{2} \mathrm{OH}, \mathrm{CH}_{3} \mathrm{O}, \mathrm{CH}_{3} \mathrm{CO} \\
\mathrm{CH}_{3} \mathrm{CHO}, \mathrm{CH}_{3} \mathrm{COO}\end{array}$ & 1420 & $\mathrm{HCOO}$ \\
\hline$[1447,1488]$ & $\begin{array}{l}\mathrm{CH}_{3} \mathrm{COO}, \mathrm{CH}_{3} \mathrm{O}, \mathrm{CHO}, \mathrm{COH}\left(\mathrm{T}_{2}\right), \\
\mathrm{CH}_{3} \mathrm{CO}, \mathrm{CH}_{3} \mathrm{CH}_{2} \mathrm{O}\end{array}$ & 1470 & $\mathrm{CH}_{3} \mathrm{COO}, \mathrm{CH}_{3} \mathrm{O}, \mathrm{CO}_{3}$ \\
\hline$[1535,1562]$ & $\mathrm{HCOO}$ & 1590 & $\mathrm{HCOO}$ \\
\hline$[1744,1747]$ & $\mathrm{CO}_{3}$ & -- & -- \\
\hline
\end{tabular}


Table 4. Reaction energies, $\Delta \mathrm{E}_{\text {sep }}$ and $\Delta \mathrm{E}_{\text {coad }}$, and reaction barriers, $\mathrm{E}_{\mathrm{a}}$, of different elementary steps for CO hydrogenation at the $\mathrm{MoS}_{2}(10-10)$ surface. For definitions of $\Delta \mathrm{E}_{\text {sep }}, \Delta \mathrm{E}_{\text {coad }}$, $\mathrm{E}_{\mathrm{a}}$, see text. All energies are given in $\mathrm{eV}$. The numbers in parentheses refer to theoretical values for a pure Mo metal termination [35], also labeled with "a", see Fig. 1 and text.

\begin{tabular}{|c|c|c|c|c|c|c|}
\hline \multirow[t]{2}{*}{ Reaction step } & \multicolumn{3}{|c|}{$\mathrm{T}_{1}{ }^{\prime}$ termination } & \multicolumn{3}{|c|}{$\mathrm{T}_{2}$ termination } \\
\hline & $\Delta \mathrm{E}_{\mathrm{sep}}$ & $\Delta \mathrm{E}_{\text {coad }}$ & $\mathrm{E}_{\mathrm{a}}$ & $\Delta \mathrm{E}_{\mathrm{sep}}$ & $\Delta \mathrm{E}_{\text {coad }}$ & $\mathrm{E}_{\mathrm{a}}$ \\
\hline \multicolumn{7}{|l|}{$\mathrm{CO}+\mathrm{H}$} \\
\hline $\mathrm{CO}+\mathrm{H} \rightarrow \mathrm{CHO}$ & 0.11 & $0.36\left(0.51^{\mathrm{a}}\right)$ & 1.45 & 0.15 & 0.23 & 0.81 \\
\hline $\mathrm{CO}+\mathrm{H} \rightarrow \mathrm{COH}$ & 0.54 & $0.79\left(1.71^{\mathrm{a}}\right)$ & 1.75 & 1.33 & 1.46 & 3.52 \\
\hline $\mathrm{CHO} \rightarrow \mathrm{CH}+\mathrm{O}$ & 0.21 & $0.80\left(-0.69^{\mathrm{a}}\right)$ & $1.46\left(0.50^{\mathrm{a}}\right)$ & 0.13 & -0.23 & 2.53 \\
\hline \multicolumn{7}{|l|}{$\mathrm{CO}+2 \mathrm{H}$} \\
\hline $\mathrm{CHO}+\mathrm{H} \rightarrow \mathrm{CH}_{2} \mathrm{O}$ & -0.13 & $-0.48\left(0.20^{\mathrm{a}}\right)$ & 0.79 & -0.21 & 0.06 & 1.23 \\
\hline $\mathrm{CHO}+\mathrm{H} \rightarrow \mathrm{CHOH}$ & 0.36 & $0.00\left(1.00^{\mathrm{a}}\right)$ & 1.06 & 0.28 & 0.64 & 1.73 \\
\hline $\mathrm{CH}_{2} \mathrm{O} \rightarrow \mathrm{CH}_{2}+\mathrm{O}$ & 0.04 & $-0.28\left(-0.73^{\mathrm{a}}\right)$ & $1.47\left(0.31^{\mathrm{a}}\right)$ & 0.17 & 0.02 & 1.87 \\
\hline \multicolumn{7}{|l|}{$\mathrm{CO}+3 \mathrm{H}$} \\
\hline $\mathrm{CH}_{2} \mathrm{O}+\mathrm{H} \rightarrow \mathrm{CH}_{3} \mathrm{O}$ & -1.48 & -1.36 & 1.60 & -0.96 & -0.84 & 1.43 \\
\hline $\mathrm{CH}_{2} \mathrm{O}+\mathrm{H} \rightarrow \mathrm{CH}_{2} \mathrm{OH}$ & -0.65 & -0.52 & 0.88 & -0.20 & -0.10 & 0.63 \\
\hline $\mathrm{CH}_{3} \mathrm{O} \rightarrow \mathrm{CH}_{3}+\mathrm{O}$ & 0.68 & 1.35 & 2.59 & 0.52 & 0.76 & 2.26 \\
\hline $\mathrm{CH}_{2} \mathrm{OH} \rightarrow \mathrm{CH}_{2}+\mathrm{OH}$ & -0.32 & -0.29 & 0.95 & -0.47 & -0.56 & 0.95 \\
\hline \multicolumn{7}{|l|}{ Misc } \\
\hline $\mathrm{CH}_{2} \mathrm{OH}+\mathrm{H} \rightarrow \mathrm{CH}_{3} \mathrm{OH}$ & -0.46 & -0.78 & 1.26 & -0.81 & -0.62 & 1.60 \\
\hline $\mathrm{CH}_{2}+\mathrm{H} \rightarrow \mathrm{CH}_{3}$ & -0.84 & $-0.20\left(-0.01^{\mathrm{a}}\right)$ & 0.97 & -0.60 & -0.57 & 0.79 \\
\hline $\mathrm{CH}_{3}+\mathrm{H} \rightarrow \mathrm{CH}_{4}$ & -0.70 & $-1.26\left(0.42^{\mathrm{a}}\right)$ & $0.53\left(0.58^{\mathrm{a}}\right)$ & -0.86 & -0.98 & 1.09 \\
\hline $\mathrm{CH}_{3}+\mathrm{OH} \rightarrow \mathrm{CH}_{3} \mathrm{OH}$ & 0.67 & -0.38 & 1.68 & 0.26 & 0.32 & 3.57 \\
\hline
\end{tabular}




\section{FIGURE CAPTIONS}

Fig. 1. Crystal structure of hexagonal $\mathrm{MoS}_{2}$ at the (10-10) surface with (a) ideal bulk termination, (b) sulfur reconstructed termination, see text. Molybdenum (sulfur) centers are shown by small dark (large light) balls with connecting sticks visualizing atom coordination. The two differently Mo and S terminated layers are labeled accordingly.

Fig. 2. Slabs of (a) $\mathrm{T}_{1}$ ' terminated, (b) $\mathrm{T}_{2}$ terminated $\mathrm{MoS}_{2}$ sheets used for the supercell model systems, see text. Molybdenum (sulfur) centers are shown by small dark (large light) balls with connecting sticks visualizing atom coordination. Vector $\mathrm{R}_{\mathrm{s}}$ denotes the supercell periodicity along the sheet edge including six $\mathrm{MoS}_{\mathrm{x}}$ units.

Fig. 3. Computed equilibrium geometries of selected $\mathrm{C}_{1}$ reaction intermediates at $\mathrm{T}_{1}$ ' and $\mathrm{T}_{2}$ terminated edges of the $\mathrm{MoS}_{2}$ (10-10) surface, (a) $\mathrm{CHO}$; (b) $\mathrm{COH}$; (c) $\mathrm{CHOH}$; (d) $\mathrm{CH}_{2} \mathrm{O}$; (e) $\mathrm{CH}_{2} \mathrm{OH}$; and (f) $\mathrm{CH}_{3} \mathrm{O}$. The atom centers are shown by shaded balls of different size and labeled in Fig. 3a. Connecting sticks are meant to visualize atom coordination.

Fig. 4. Computed equilibrium geometries of selected $\mathrm{C}_{1}$ and $\mathrm{C}_{2}$ type reaction intermediates at $\mathrm{T}_{1}$ ' and $\mathrm{T}_{2}$ terminated edges of the $\mathrm{MoS}_{2}(10-10)$ surface, (a) $\mathrm{HCOO}$; (b) $\mathrm{CO}_{3}$; (c) $\mathrm{CH}_{3} \mathrm{CO}$; (d) $\mathrm{CH}_{3} \mathrm{CHO}$; (e) $\mathrm{CH}_{3} \mathrm{CH}_{2} \mathrm{O}$; (f) $\mathrm{CH}_{3} \mathrm{COO}$. The atom centers are shown by shaded balls of different size and labeled in Fig. 4a. Connecting sticks are meant to visualize atom coordination.

Fig. 5. Computed equilibrium geometries of selected $\mathrm{CH}_{\mathrm{x}}$ species at $\mathrm{T}_{1}$ ' and $\mathrm{T}_{2}$ terminated edges of the $\mathrm{MoS}_{2}\left(10-10\right.$ ) surface, (a) $\mathrm{C}$; (b) $\mathrm{CH}$; (c) $\mathrm{CH}_{2}$; (d) $\mathrm{CH}_{3}$. The atom centers are shown by shaded balls of different size and labeled in Fig. 5a. Connecting sticks are meant to visualize atom coordination.

Fig. 6. Sequential CO hydrogenation steps at the $\mathrm{T}_{1}{ }^{\prime}$ edge for the most favorable reaction path: The structures to the left denote initial reactants, those on the right refer to products, and the center structures sketch corresponding transition states.

Fig. 7. Sequential CO hydrogenation steps at the $\mathrm{T}_{2}$ edge for the most favorable reaction path: The structures to the left denote initial reactants, those on the right refer to products, and the center structures sketch corresponding transition states.

Fig. 8. Energetic reaction schemes for sequential CO hydrogenation at the (a) $\mathrm{T}_{1}$ ' edge and (b) $\mathrm{T}_{2}$ edge assuming reaction intermediates and products in their adsorbed states at the surface. The most favorable reaction paths are highlighted by thick lines. Alternative intermediates are labeled accordingly and listed at the bottom of the graph. The barriers between the reaction intermediates refer to corresponding reaction barriers. 
[1] M. Saito, R.B. Anderson, J. Catal. 63 (1980) 438.

[2] C.B. Murchison, M.M. Conway, R.R. Stevens, G.J. Guarderer, Proc. 9th Int. Congress on Catalysis 2 (1988) 626.

[3] J.S. Lee, S. Kim, K.H. Lee, I.S. Nam, J.S. Chung, Y.G. Kim, H.C. Woo, Appl. Catal. A 110 (1994) 11.

[4] Y. Xie, B.N. Naasz, G.A. Somorjai, Appl. Catal. 27 (1986) 233.

[5] J. Zhang, Y. Wang, L. Chang, Appl. Catal. A 126 (1995) L205.

[6] Y. Avila, C. Kappenstein, S. Pronier, J. Barrault, Appl. Catal. A 132 (1995) 97.

[7] Z.-R. Li, Y.-L. Fu, M. Jiang, T.-D. Hu, T. Liu, Y.-N. Xie, J. Catal. 199 (2001) 155.

[8] N. Koizumi, G. Bian, K. Murai, T. Ozaki, M. Yamada, J. Mol. Catal. A: Chem. 207 (2004) 173.

[9] Z. Li, Y. Fu, J. Bao, M. Jiang, T. Hu, T. Liu, Y. Xie, Appl. Catal. A 220 (2001) 21.

[10] D. Li, C.Yang, H. Qi, H. Zhang, W. Li, Y. Sun, B. Zhong, Catal. Commun. 5 (2004) 605.

[11] D. Li, C.Yang, W. Li, Y. Sun, B. Zhong, Top. Catal. 32 (2005) 233.

[12] R.G. Herman, Catal. Today 55 (2000) 233.

[13] T. Tatsumi, A. Muramatsu, K.Yokota, H. Tominaoa, J. Catal. 115 (1989) 388.

[14] S.C. Chuang, Y.H. Tian, J.G. Goodwin Jr., I. Wender, J. Catal. 96 (1985) 396.

[15] J.G. Numan, C.E. Bogdan, K. Kiler, K.J. Smith, C.-W. Young, R.G. Herman, J. Catal. 116 (1989) 195.

[16] T.Y. Park, I.-S. Nam, Y.G. Kim, Ind. Eng. Chem. Res. 36 (1997) 5246.

[17] J.G. Santiesteban, C.E. Bogdan, R.G. Herman, K. Klier, Proc. 9th Int. Congress on Catalysis $2(1988) 561$.

[18] A. Kiennemann, S. Boujana, C. Diagne, P. Chaumette, Stud. Surf. Sci. Catal. 75 (1993) 1479.

[19] A. Kiennemann, S. Boujana, C. Diagne, P. Courty, P. Chaumette, Stud. Surf. Sci. Catal. 61 (1991) 243.

[20] A. Travert, H. Nakamura, R.A. van Santen, S. Cristol, J.-F. Paul, E. Payen, J. Am. Chem. Soc. 124 (2002) 7084. 
[21] Y.-W. Li, X.-Y. Pang, B. Delmon, J. Mol. Catal. A 169 (2001) 259.

[22] P. Faye, E. Payen, D. Bougeard, J. Catal. 179 (1998) 560.

[23] L.S. Byskov, J.K. Nørskov, B.S. Clausen, H. Topsøe, J. Catal. 187 (1999) 109.

[24] H. Schweiger, P. Raybaud, G. Kresse, H. Toulhoat, J. Catal. 207 (2002) 76.

[25] Á. Logadóttir, P.G. Moses, B. Hinnemann, N.-Y. Topsøe, K.G. Knudsen, H. Topsøe, J.K. Nørskov, Catal. Today 111 (2006) 44.

[26] V. Alexiev, R. Prins, T. Weber, Phys. Chem. Chem. Phys. 2 (2000) 1815.

[27] M.V. Bollinger, K.W. Jacobsen, J.K. Nørskov, Phys. Rev. B 67 (2003) 085410.

[28] M. Sun, A.E. Nelson, J. Adjaye, Catal. Today 105 (2005) 36.

[29] S. Cristol, J.F. Paul, E. Payen, J. Phys. Chem. B 106 (2002) 5659.

[30] (a) T. Zeng, X.-D. Wen, G.-S. Wu, Y.-W. Li, H. Jiao, J. Phys. Chem. B 109 (2005) 2846. (b) T. Zeng, X.-D. Wen, Y.-W. Li, H. Jiao, J. Phys. Chem. B 109 (2005) 13704. (c) T. Zeng, X.-D. Wen, Y.-W. Li, H. Jiao, J. Mol. Catal. A 241 (2005) 219. (d) X.-D. Wen, T. Zeng, H. Jiao, J. Phys. Chem. B 110 (2006) 14004.

[31] X.-D. Wen, T. Zeng, B.-T. Teng, F.-Q. Zhang, Y.-W. Li, J. Wang, H. Jiao, J. Mol. Catal. A 249 (2006) 191.

[32] A. Travert, C. Dujardin, F. Maugé, S. Cristol, J.-F. Paul, E. Payen, D. Bougeard, Catal. Today 70 (2001) 255.

[33] P. Raybaud, J. Hafner, G. Kresse, S. Kasztelan, H. Toulhoat, J. Catal. 189 (2000) 129.

[34] S. Cristol, J.F. Paul, E. Payen, D. Bougeard, S. Clémendot, F. Hutschka, J. Phys. Chem. B $104(2000) 11220$.

[35] M. Huang, K. Cho, J. Phys. Chem. C 113 (2009) 5238.

[36] M. Sun, J. Adjaye, A.E. Nelson, Appl. Catal. A 263 (2004) 131.

[37] J.V. Lauritsen, M. Nyberg, J.K. Nørskov, B.S. Clausen, H. Topsøe, E. Lægsgaard, F. Besenbacher, J. Catal. 224 (2004) 94.

[38] B. Delley, J. Chem. Phys. 92 (1990) 508.

[39] B. Delley, J. Chem. Phys. 113 (2000) 7756.

[40] J.P. Perdew, Y. Wang, Phys. Rev. B 45 (1992) 13244.

[41] J.P. Perdew, J.A. Chevary, S.H. Vosko, Phys. Rev. B 46 (1992) 6671. 
[42] M. Dolg, U. Wedig, H. Stoll, H. Preuss, J. Chem. Phys. 86 (1987) 866.

[43] A. Bergner, M. Dolg, W. Kuechle, H. Stoll, H. Preuss, Mol. Phys. 80 (1993) 1431.

[44] T.A. Halgren, W.N. Lipscomb, Chem. Phys. Lett. 49 (1977) 225.

[45] G. Kresse, J. Furthmüller, Comput. Mater. Sci. 6 (1996) 15.

[46] G. Kresse, J. Furthmüller, Phys. Rev. B 54 (1996) 11169.

[47] T. Todorova, R. Prins, Th. Weber, J. Catal. 236 (2005) 190.

[48] B. Delmon, Bull. Soc. Chim. Belg. 88 (1979) 979.

[49] (a) X.-Q. Yao, Y.-W. Li, H. Jiao, J. Mol. Struct. (Theochem) 726 (2005) 67. (b) X.-Q. Yao, Y.-W. Li, H. Jiao, J. Mol. Struct. (Theochem) 726 (2005) 81.

[50] B. Delmon, G.F. Froment, Catal. Rev. Sci. Eng. 38 (1996) 69.

[51] S.K. Desai, M. Neurock, K. Kourtakis, J. Phys. Chem. B 106 (2002) 2559.

[52] G.R. Bamwenda, A. Ogata, A. Obuchi, J. Oi, K. Mizuno, J. Skrzypek, Appl. Catal. B 6 (1995) 311.

[53] C.N. Hinshelwood, Kinetics of Chemical Changes, Oxford, Clarendon Press, U.K. (1940) 197.

[54] (a) S.-G. Wang, D.-B. Cao, Y.-W. Li, J. Wang, H. Jiao, J. Phys. Chem. B 110 (2006) 9976.

(b) C. Huo, J. Ren, Y. Li, J. Wang, H. Jiao, J. Catal. 249 (2007) 174. (c) O.R. Inderwildi,

S.J. Jenkins, D.A. King, J. Phys. Chem. C 112 (2008) 1305. (d) C. Huo, Y. Li, J. Wang, H. Jiao, J. Phys. Chem. C 112 (2008) 14108. (e) O.R. Inderwildi, S.J. Jenkins, D.A. King, Angew. Chem. Int. Ed. 47 (2008) 5253.

[55] S.-G. Wang, X.-Y. Liao, J. Hu, D.-B. Cao, Y.-W. Li, J.G. Wang, H. Jiao, Surf. Sci. 601 (2007) 1271.

[56] R.N. Nickolov, R.M. Edreva-Kardjieva, V.J. Kafedjiysky, D.A. Kikolova, N.B. Stankova, D.R. Mehandjiev, Appl. Catal. A 190 (2000) 191.

[57] P. Hou, D. Meeker, H. Wise, J. Catal. 80 (1983) 280.

[58] M. Kantschewa, F. Delannay, H. Jeziorowski, E. Delgado, S. Eder, G. Ertl, J. Catal. 87 (1984) 482.

[59] V. Kettmann, P. Balgavy, L. Sokol, J. Catal. 112 (1988) 93.

[60] M. Łaniecki, M. Małecka-Grycz, F. Domka, Appl. Cata. A 196 (2000) 293. 
[61] X.-R. Shi, S.-G. Wang, J. Hu, Y.-Y Chen, Z. Qin, J. Wang, Appl. Cata. A 365 (2009) 62. 
(a) Mo $\mathrm{S} \quad$ Mo term. Sterm.

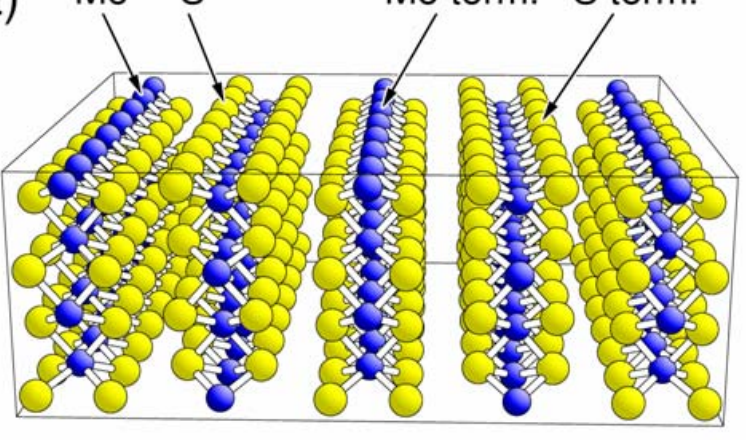

(b)

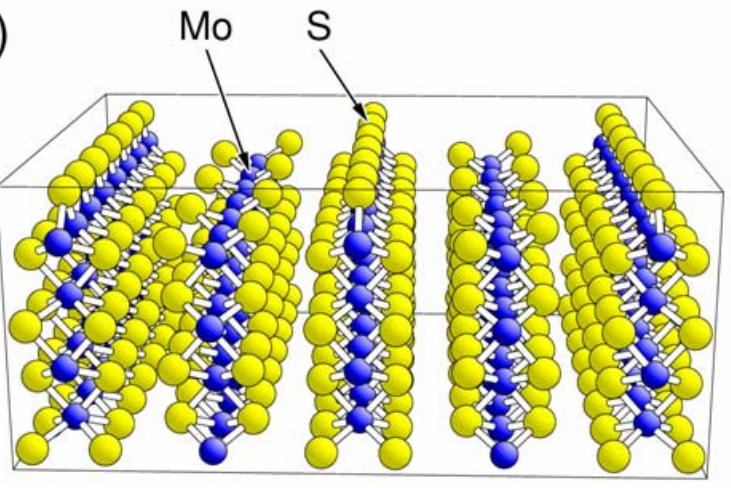


(a) $\mathrm{T}_{1}$ ' term.

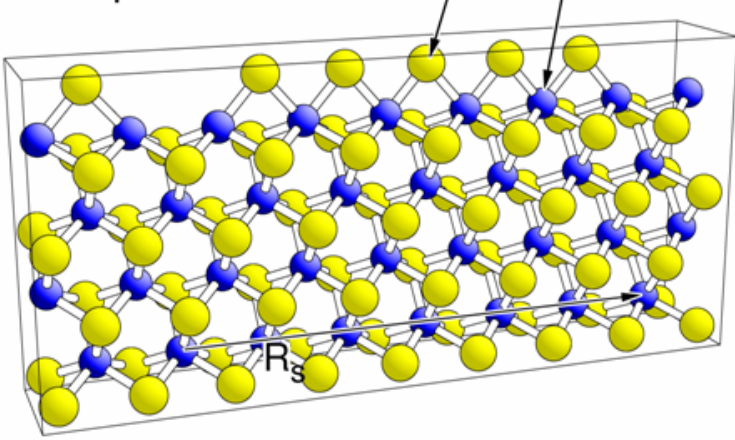

(b) $\mathrm{T}_{2}$ term.

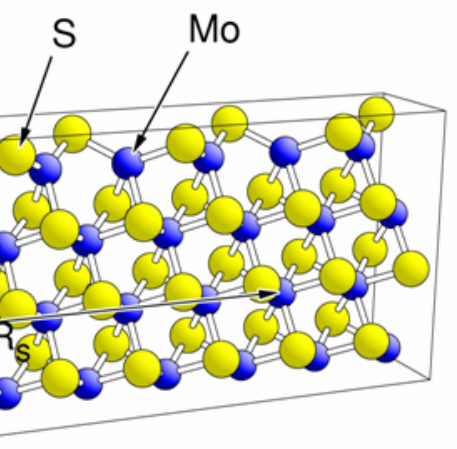


(a) $\mathrm{CHO}$

(b) $\mathrm{COH}$
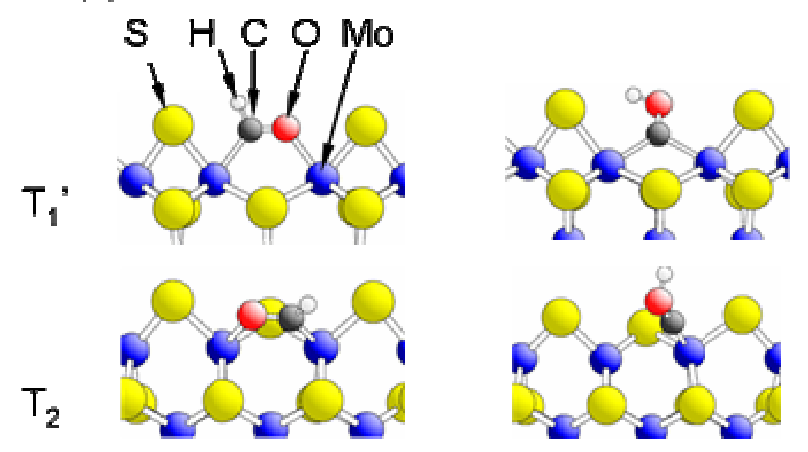

(c) $\mathrm{CHOH}$

(d) $\mathrm{CH}_{2} \mathrm{O}$

$T_{1}{ }^{\prime}$
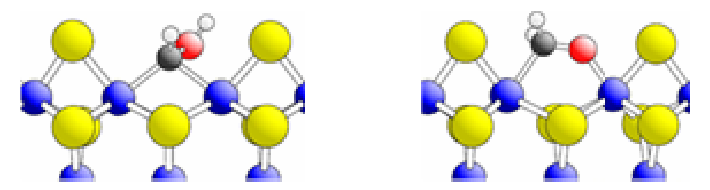

$\mathrm{T}_{2}$
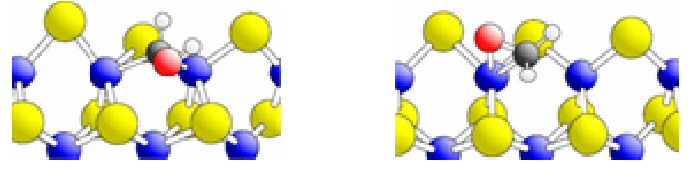

(e) $\mathrm{CH}_{2} \mathrm{OH}$

(f) $\mathrm{CH}_{3} \mathrm{O}$

$T_{1}$
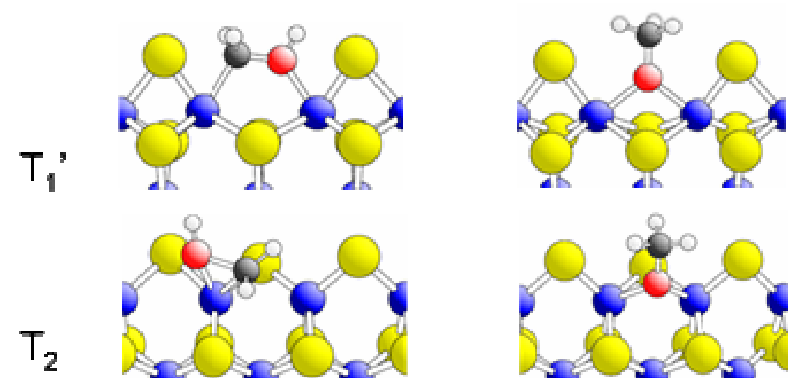


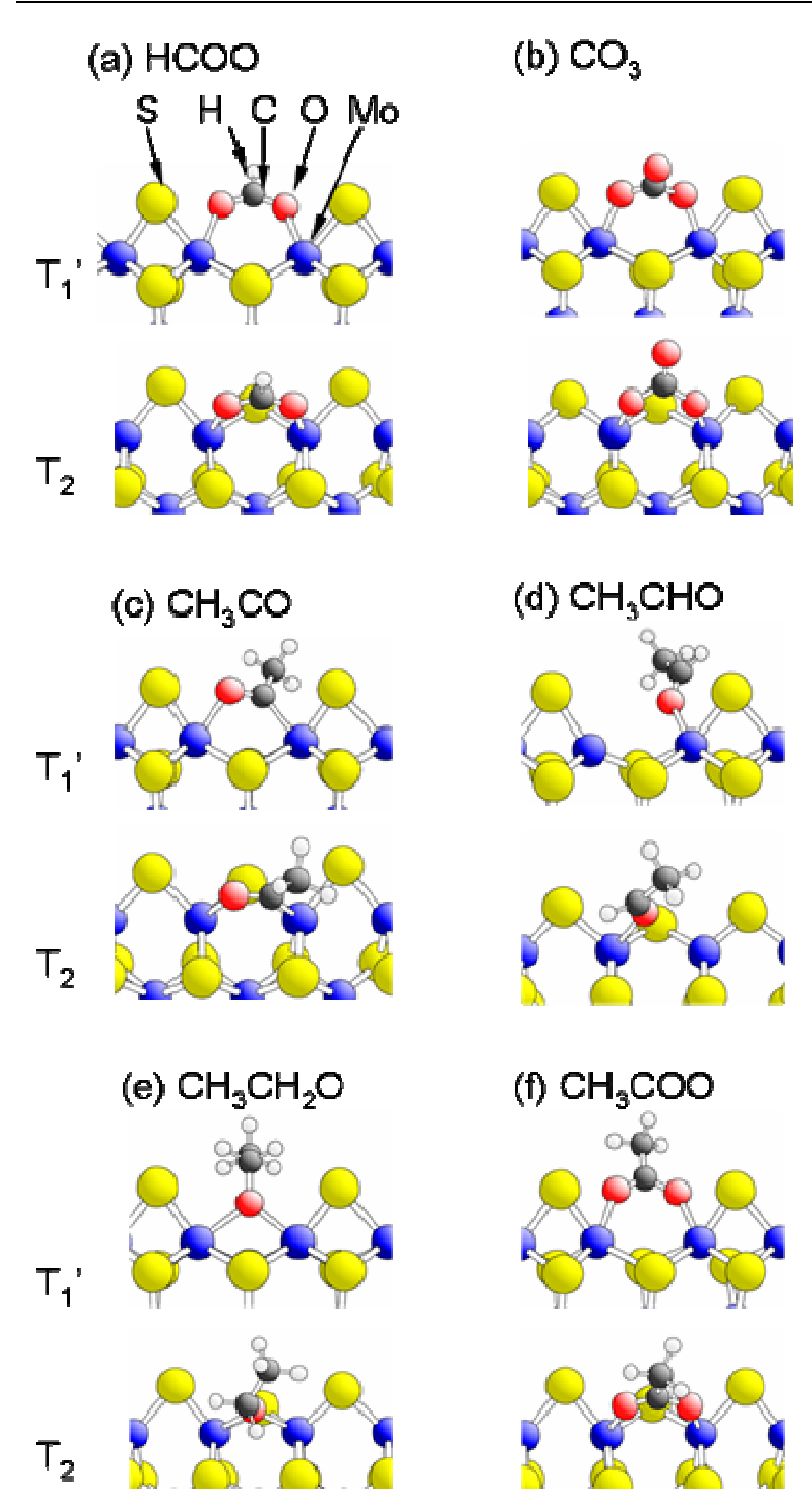


(a) $\mathrm{C}$

(b) $\mathrm{CH}$

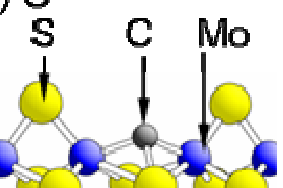

$T^{\prime}{ }^{\prime}$
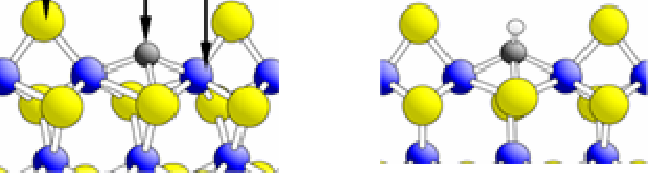

$T_{2} x_{20}$

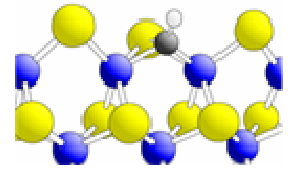

(c) $\mathrm{CH}_{2}$

(d) $\mathrm{CH}_{3}$
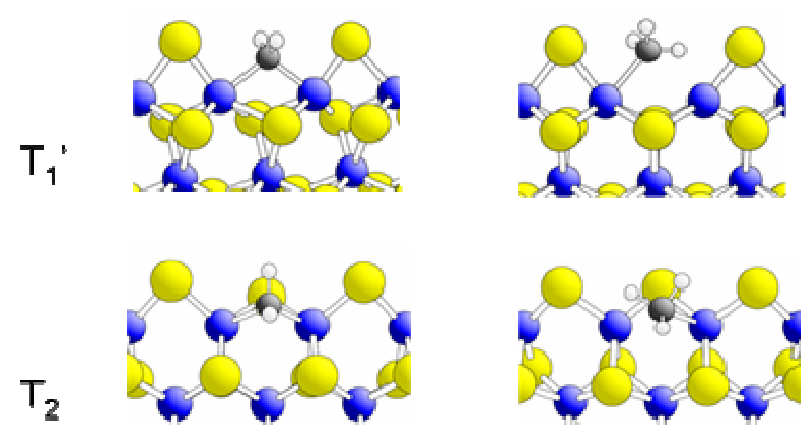
(a) $\mathrm{CO}+\mathrm{H} \longrightarrow \mathrm{CHO}$

Q.8

(b) $\mathrm{CHO}+\mathrm{H} \longrightarrow \mathrm{CH}_{2} \mathrm{O}$

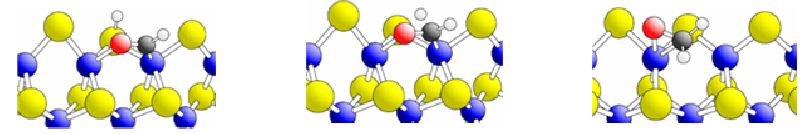

(c) $\mathrm{CH}_{2} \mathrm{O}+\mathrm{H} \longrightarrow \mathrm{CH}_{2} \mathrm{OH}$

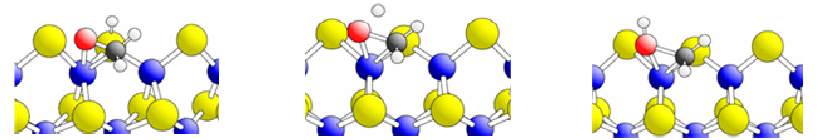

$\mathrm{CH}_{2} \mathrm{OH} \longrightarrow \mathrm{CH}_{2}+\mathrm{OH}$

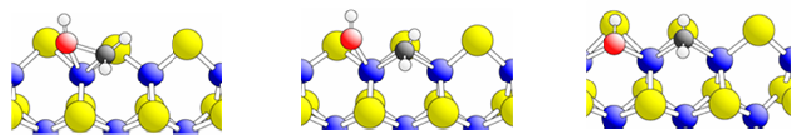

(d) $\mathrm{CH}_{2}+\mathrm{H} \longrightarrow \mathrm{CH}_{3}$

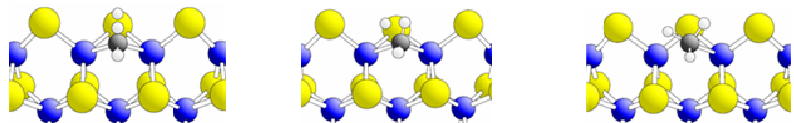

$\mathrm{CH}_{3}+\mathrm{H} \longrightarrow \mathrm{CH}_{4}$

Q.". 
(a) $\mathrm{CO}+\mathrm{H} \longrightarrow \mathrm{CHO}$

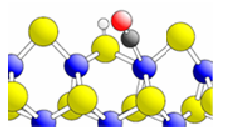

so

(b) $\mathrm{CHO}+\mathrm{H} \longrightarrow \mathrm{CH}_{2} \mathrm{O}$

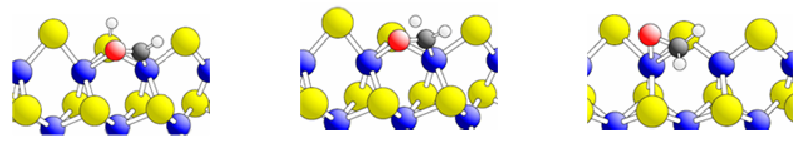

(c) $\mathrm{CH}_{2} \mathrm{O}+\mathrm{H} \longrightarrow \mathrm{CH}_{2} \mathrm{OH}$

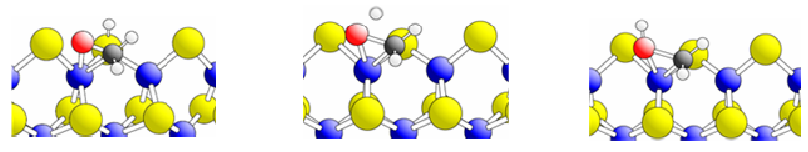

$\mathrm{CH}_{2} \mathrm{OH} \longrightarrow \mathrm{CH}_{2}+\mathrm{OH}$

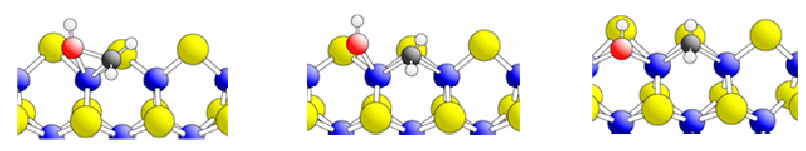

(d) $\mathrm{CH}_{2}+\mathrm{H} \longrightarrow \mathrm{CH}_{3}$

So, a

$\mathrm{CH}_{3}+\mathrm{H} \longrightarrow \mathrm{CH}_{4}$

Q. 
(a)

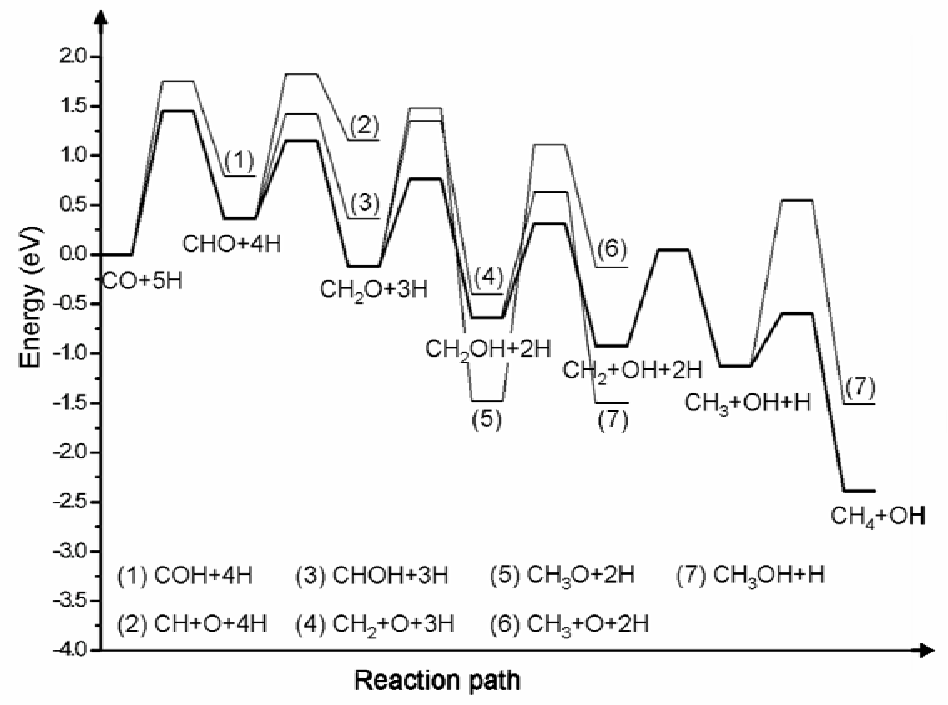

(b)

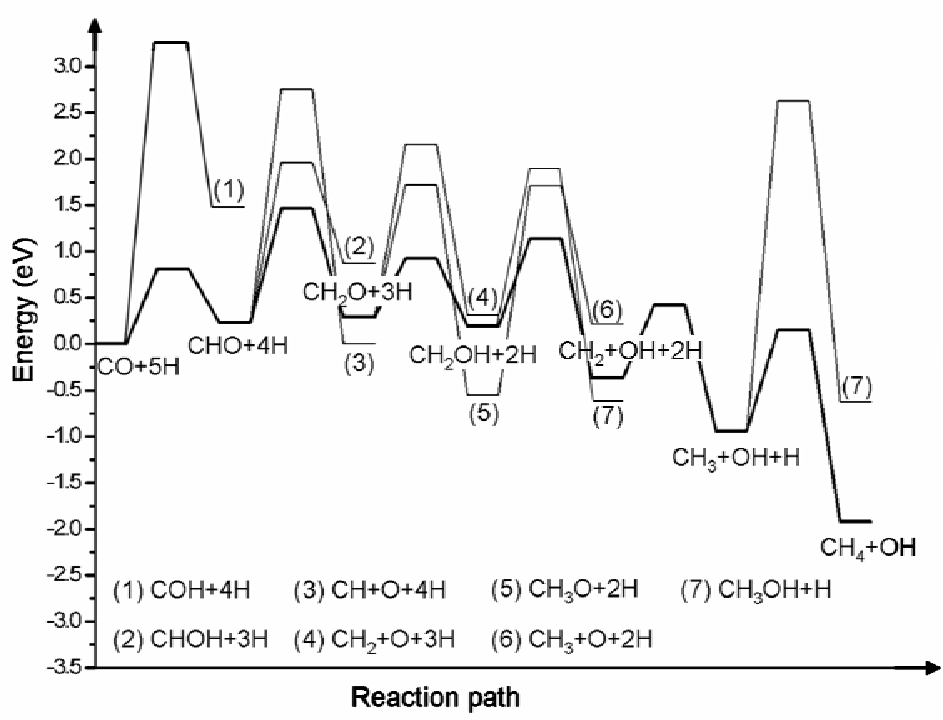

